Article

\title{
Territorial Effects of Shared-Living Heritage Regeneration
}

\author{
Tiziano Cattaneo ${ }^{1,2, *}$, Emanuele Giorgi ${ }^{3}{ }^{10}$, Mauricio Flores ${ }^{3}$ and Viviana Barquero ${ }^{4}$ \\ 1 Environmental Futures Lab., College of Design and Innovation, Tongji University, n. 281 Fuxin Road, \\ Yangpu District, Shanghai 200092, China \\ 2 China Lab. for Architecture and Urban Studies, Department of Civil Engineering and Architecture, \\ University of Pavia, Via Ferrata 1, 27100 Pavia, Italy \\ 3 Tecnologico de Monterrey, Escuela de Arquitectura, Arte y Diseño Av. H. Colegio Militar 4700, \\ Nombre de Dios, Chihuahua 31300, Mexico; egiorgi@tec.mx (E.G.); alfredomauricio.flores@tec.mx (M.F.) \\ 4 Tecnologico de Monterrey, Escuela de Arquitectura, Arte y Diseño Av. Eugenio Garza Sada S/N, \\ Predio Cerro Gordo, León 37190, Mexico; viviana.barquero@tec.mx \\ * Correspondence: tiziano.cattaneo@tongji.edu.cn
}

Received: 30 June 2020; Accepted: 14 October 2020; Published: 17 October 2020

\begin{abstract}
The paper presents further steps of study started by authors in recent years, as part of the widest international research collaboration, which focuses on shared life and regeneration of abandonment of rural settlements as strategies for the development of sustainable territories. This research aims to understand how the regeneration of ancient community buildings impacts on the sustainable development of the local context. To understand these effects, the research considered four traditional typologies of community buildings, from different cultures: Tulou (China), Cascina (Italy), Hacienda (Mexico), and Marae (New Zealand). Among the tens/hundreds of contemporary regeneration interventions, three contemporary projects per each of these typologies have been selected. To assess the territorial impact of the projects a new approach has been defined using Expert Interviews as the methodology, so as to be able to have an assessment directly by experts in the fields of regenerative projects and sustainable development. The Expert Interviews were held based on a questionnaire that assessed the effects of the projects. For the evaluation of the projects, two categories of indicators have been selected: (1) United Nations SDGs, (2) architectural regeneration indicators generated by the study "The Role of Cultural Heritage in Sustainable Development: Multidimensional Indicators as Decision-Making Tool", by Francesca Nocca, published in Sustainability $(2017,9,1882)$. The research outputs show how the urban-architectural regeneration of these historical typologies can be clearly associated with indications of sustainable development. The results also show that in all four cultures the regeneration of historic buildings provides many benefits to local communities by successfully mixing different income groups and the inclusion of marginalized or vulnerable groups.
\end{abstract}

Keywords: shared heritage; architectural design; heritage regeneration; community buildings; expert interview method; sustainable development goals (SDGs); cultural landscape; territorial impacts and sustainability; rural-urban

\section{Introduction}

The idea that regeneration practices are related to the sustainable development of territories, cities, and local communities is now established in contemporary academic literature as well as in common awareness [1,2]. In fact, the association between regenerative practices and sustainable development is not limited to the academic sphere but it is strongly accepted both by the urban-architectural design practice, and the government sector which increasingly promotes regeneration projects to 
encourage sustainable solutions [3-5]. Moreover, these two aspects together bring about results in other fields, such as tourism [6,7], disaster prevention [8], urban planning [9,10], and decision-making processes [11].

The work presented in this article focuses on the role sustainable territorial development has in those regenerative interventions made using traditional types of collective buildings. The decision to focus on traditional collective buildings is dictated by the curiosity to observe how buildings, which traditionally have been fundamental elements in defining the urban-architectural structure and the social rules of almost all cultures [12], react to regenerative projects that often changes the building functional program and its relationship with the context.

Projects that intervene on historical heritage-and, in particular, on architectural typologies that often represented the symbol of a community or, furthermore, were the very essence of a society [12] —are now very common. It is therefore urgent to understand how territories and local communities are impacted by project regeneration, by being able to identify, first, the positive and negative effects and, second, define key design decisions on how to deal with these projects.

\subsection{Shared Life in History}

Active participation in community life has always been a key factor for human communities and the spatial organization of communities allows this type of involvement. For this, innumerable examples of community buildings can be found in almost all human housing cultures. Community buildings played a fundamental role in these cultures as promoters of the sense of belonging to a community and a protective element from external dangers. This historical heritage, which in the article will be defined as Shared Living Heritage (SLH), has still remained as a symbol of the various housing cultures, even if often the functions have changed or the buildings have fallen into disuse. Around them, community members can still recognize each other and retain a clear identity so that they can be considered within the so-called historical landscape elements (HLE) [13-17], or "fundamental components of cultural landscapes, becoming important bearers of collective services" [13].

\subsection{Regeneration as Sustainable Practice in Contemporary Territories}

Common regeneration projects in contemporary territories are seen in historic places whether urban or rural, particularly as an evolutionary necessity of community in response to many of the challenges posed by worldwide changes affecting the way of many people's lives [18,19]. The need to rediscover natural forms of relationships pushes to think of new forms of producing, living, and experiencing. Therefore, we see more abandoned buildings and other kinds of historic properties are becoming objects of regeneration as a way to establish new forms of communitarian living. Practices of social and environmental sustainability are combined, reducing consumption of land, landscape coherence, territorial intensification, and affordable way of life.

Since the early 1980s, the concept of counter-urbanization [20] became an answer to the issues of living in urban areas. In his seminal paper in 1985, Paul Cloke [20] argued that shortage in affordable housing, increase in basic service costs, the growth of rural economic activities as an alternative to unhealthy city life, teleworking/home office opportunities, and schedule flexibility in corporate activities, has triggered the possibility of living outside urban settings. Currently, there are several approaches to regeneration. From touristic to environmental services; from a more social/community-led approach to a more holistic perspective, the reality is that historic-rural settlements are used to comply with all the needs and desires of new generations eager to try something different from what they live nowadays $[21,22]$.

\subsubsection{Regeneration of Historical Heritage}

In general, the regeneration of historical heritage interplays with many factors concerning the physical, environmental, economic, and social aspects. Among others, the communities recognize a historical site or building-specific values and identity. 
Particularly in cultural and natural landscapes, a community advocates its value to sacred or historical/patriotic events, creating a sense of nostalgia. This reinforces the fundamental relationship between natural and built features, recognizing its profound legacy to the community. Therefore, it is important to consider the intrinsic value of the site when proposing a regeneration project and should account for these premises in order to be successful.

Regeneration strategies vary widely around the world, depending on the policies that each country has regarding preservation and stewardship, but also to the level of association and cultural recognition a site or building is exposed to. Each country has its own preservation measures promoting some sort of stewardship in order to take care of the regenerated site. Depending on the site, a private investor, a public-private agreement, a non-profit organization, and of course, the community itself, could be the principal steward of the historic regenerated site [23].

There are varied arguments as to whether we should regenerate heritage and for what purposes. On one hand, we found studies that celebrate the economic and social benefits that heritage conservation and regeneration brings to the community $[24,25]$ but on the other, more skeptical authors argue that the reaction of nostalgic elements attached to the specific site, or the more personal motives that some community members may have to regenerate heritage, actually rejects a more organic, local, diverse, and authentic use of the space [26,27].

Several movements such as some branches of the new urbanism model, shared living practices, and cohousing strategies, have become an outstanding way to regenerate and reutilize historical heritage in urban and rural settings. These movements have found that old buildings and sites respond to dwelling necessities while celebrating key cultural elements of the community that would live within, disregarding bad habits of cultural appropriation and cliché redefinitions of authenticity.

Recognizing the living dimension of historic heritage sites to regenerate and reutilize them in a more sustainable approach, is a useful way to build a sense of community through social interaction and aspects associated with local heritage, as well as promoting community life and a sense of place.

\subsubsection{Historic Urban Landscapes}

The concept of Historic Urban Landscapes (HULs) is not new, but its potential in today's world is. The concept draws from experience in urban conservation and cultural landscapes, seeking to encompass values relating to intangible heritage, genius loci, authenticity, and integrity [28,29].

HULs extend beyond the traditional boundaries of historic cities or districts to encompass the larger territory of their urban, rural, and/or natural settings, which also require conservation and management. The physical character of HULs is defined as much by their urban and architectural traits as by their natural setting, the geographic elements that preceded them and shaped their growth, and the resulting viewsheds.

Managing an HUL focuses on the dual challenge of enhancing the vitality of historic cities and of integrating contemporary architecture in an emerging conceptualization of historic cities as historic urban landscapes [30]. Traditionally, the authenticity of a place has been linked to materials, design, workmanship, and setting - the importance of physical tangible evidence. However, the original character of some places was not defined by human-made elements but by natural formations or the more ethereal concept of genius loci. According to Gustavo Araoz [30], this apparent need to venerate and preserve the material legacy inherited from the past has been codified by conservation experts through the attribution of two types of values to the materiality of place: the aesthetic value and the historic value. This means that either the physical elements of these places contained communal memories or enriched the observer through sensory delight.

However, the HUL approach suggests that in historic cities the process of change per se can be an integral component of the significance of the place, and not only the aesthetic values. Association to historic or communal memories is as important as the new traces that are conceived through contemporary developments. The implications of allowing historic cities to continue to evolve along historic patterns have been explored, and experiments of individualistic "look at me" type of public 
architecture, facadism, and buildings of unprecedented heights in close proximity to historic districts allow for the integration of the HUL discourse a key statement for an integrated approach linking contemporary architecture, sustainable urban development and landscape integrity based on historic patterns, building stocks and context [29].

There are two unrelated trends in the debate of regeneration of historic urban landscapes, one being a conceptual shift in the perception of the nature of heritage places, and the second related to the accelerating demographic pressure to increase urban density [28,30]. Historic cities are being treated as laboratories for experiments on high density, gentrification, and cultural appropriation, among others, directly affecting the cultural heritage and other tangible and intangible aspects of the site.

HULs planning interventions must be conceived as an integral part of the overall urban-management effort to bring socio-economic development and a better quality of life for the existing population. Shared-living in historic urban landscapes must be promoted not only to enhance stewardship and community management towards historic sites and buildings but also as part of a more sustainable approach, remembering Carl Elefante's [31] iconic phrase "The greenest building is the one that is already built".

Historic revitalization projects are relatively smaller than traditional new developments within the same areas since historic buildings share space composition attributes that do not necessarily qualify for the specific new functions. Intergenerational projects are more likely to succeed in HULs due to traditional neighborhood amenities, and a sense of remembrance for the elderly, as well as a sense of community for new generations.

Shared-living or cohousing communities can model good preservation of historic urban settings by successfully mixing residential incomes, stabilizing vulnerable or marginalized groups, redeveloping a small neighborhood block, and redesigning the way building retrofit is done. There are several examples of how historic places are converted into shared living projects. Examples are presented and discussed in this article.

There are many benefits in retrofit projects converted into shared communities, for instance, it prolongs senior resident independence; it sees more involvement and participation in volunteerism and local politics; and finally, it enables the ability of communities to collaborate with each other showing a potential effect within a larger community [32].

The notion behind the holistic management of historic landscapes is to secure their evolutionary development, considering issues of ecological sustainability as well as geo-cultural distinctiveness and identity. It is as much people-driven as it is artifact-driven. Management is focused on the inhabitants and others who conduct their daily lives within historic urban sites, without which it becomes difficult to serve a range of activities and the essential ingredient of a sense of place.

\subsection{Literature Review, Knowledge Gap, and Research Question}

Within this framework, it is clear how the current literature highlights (1) the great value that architectural typologies of shared living have for communities and territories and (2) the sustainable characteristics that often characterize the heritage regenerative projects. In addition to these macro-considerations, another aspect clearly emerges: (3) the introverted attitude of the original SLHs, which saw that closing themselves outwards had the possibility of protecting the community from external dangers. Actually, this last consideration can be extended also to other SLHs that the authors decided not to consider in this work to keep the research focus. Clear examples are the Kraal, the underground building of Matmata, or the Shabono [12,33-35]. Finally, (4) considering how these architectural enclosure providing the protection needed for have changed in the vast majority of cases, the research question that led to the development of this work emerges: now that these typologies are opening up to the local context-not dangerous anymore. Do SLH continue to be an element of valorization of local communities as well as a promoter for territorial sustainable development? And, in particular, what effects do these regenerative projects have on territories and local communities? Our research discusses how the urban-architectural regeneration of these historical typologies can often be clearly associated with indications of sustainable development. 


\section{Materials and Methods}

To answer the research question, the Expert Interviews methodology has been adopted as the main strategy. The panorama of Architecture Research Methodology is extremely rich and interesting [36] and, in fact, this methodology is widely used by the scientific community in the architectural-urban context as a tool for analysis and interpretation of contemporary phenomena. As argued by Meuser and Nagel "The Expert Interview as a method of qualitative empirical research, designed to explore expert knowledge, has been developed considerably since the early 1990s" [37].

The Expert Interview methodology is widely discussed, and the existing literature review provides a very clear and structured theoretical framework. Basically, this methodology, particularly used in the interpretative social research, requires that authors ask opinions to people considered "experts in their field" with the aim of (1) exploring, (2) systematizing, or (3) theory-generating [38]. There are various reasons why such a methodology could be considered adequate in fields like the one of this research: first of all, the "fact that respondents are highly qualified in the analyzed question, eliminates the need to use additional screening and clarifying questions aimed at revealing true, but hidden from the interviewer respondent views" [39]. In essence, therefore, the data obtained have the reliability that does not require additional considerations and it is possible to obtain a good representation of the studied phenomenon with relative transparency and correctness. Furthermore, as a methodology, it is flexible enough, so that it can be applied individually (as in the case of this research) or in a context of triangulation of methods [37]. However, one should not lose sight of the fact that the Expert Interview is still an interview methodology that, although providing a privileged and more reliable point of view, always remains the representation of different points of view [37]. Undoubtedly, this reliability depends very much on the correct choice of experts and on the material provided for discussion.

Who to consider as an "expert" is, in fact, very important and assumes a central role in the organization of the process. Meuser and Nagel quoting the study of Hitzler, Honer, and Maeder, provide us the definition of an expert. An "expert" is a person, who has knowledge of his own area of interest and who, at the same time, possesses an "institutionalized authority to construct reality" [37]. The importance of defining experts is emphasized also by Libakova and Sertakova who highlight how the concept of "expert" must ensure certain criteria, including, "education and skills, position, related to the research topic, work experience in the subject in question, the degree of quality of the prior expert judgments, the level of public recognition, objectivity of the submitted ratings" [39].

At the same time, the quality of the material provided to the experts, so they can develop a clear idea of the topic of discussion and evaluation, is equally important. In this sense, preparing guidelines that highlight a shared common context is recognized as an extremely effective practice, guaranteeing comparability of the results and a focus on the relevant topics against a horizon of other possibilities [37].

According to the essence of an Expert Interview methodology, the research work was structured according to the following steps: (1) definition of the types of Shared Living Heritage (SLH) to be studied, contemplating the enormous differences between housing cultures all around the world; (2) definition of recent regeneration projects and collection of a sufficient quantity of material for in-depth case studies; (3) definition of the indicators useful for studying and analyzing the territorial effects of the projects and the territorial and community role assumed by the SLH following regeneration; (4) carrying out Expert Interview according to the methods recommended by contemporary academic literature, which will be better explained later; (5) collection and analysis of the results of the Expert Interviews.

\subsection{Definition of the Four Shared Living Heritage (SLH) Typologies}

According to the research objective, four architectural typologies have been defined with the following characteristics: (1) historical relevance as community building; (2) having been the object of several regeneration projects in the last decades; (3) possibility of access to a significant quantity of material, suitable for analyzing projects. Furthermore, the four typologies have been selected in four different geographical areas and consequently are expressions from different cultures. 
The four selected typologies, which are explained in the following pictures, are Tulou (Fujian, China) [40,41], Cascina (Northern Italy, Europe) [40,42], Hacienda (Mexico) [40,43] and Marae (New Zealand) $[40,44,45]$. These typologies are explained in Figures 1-4, which represent some pages of the booklet prepared by the authors for the Expert interview. This choice was made because the authors want to show, as much as possible, the material used during the research. The 60-pages booklet used in the Expert Interview is available to everyone, at the following link (https://www.dropbox.com/s/ tp6tuhetr9u8r8z/Expert\%20Interview_booklet.pdf?dl=0) [46].

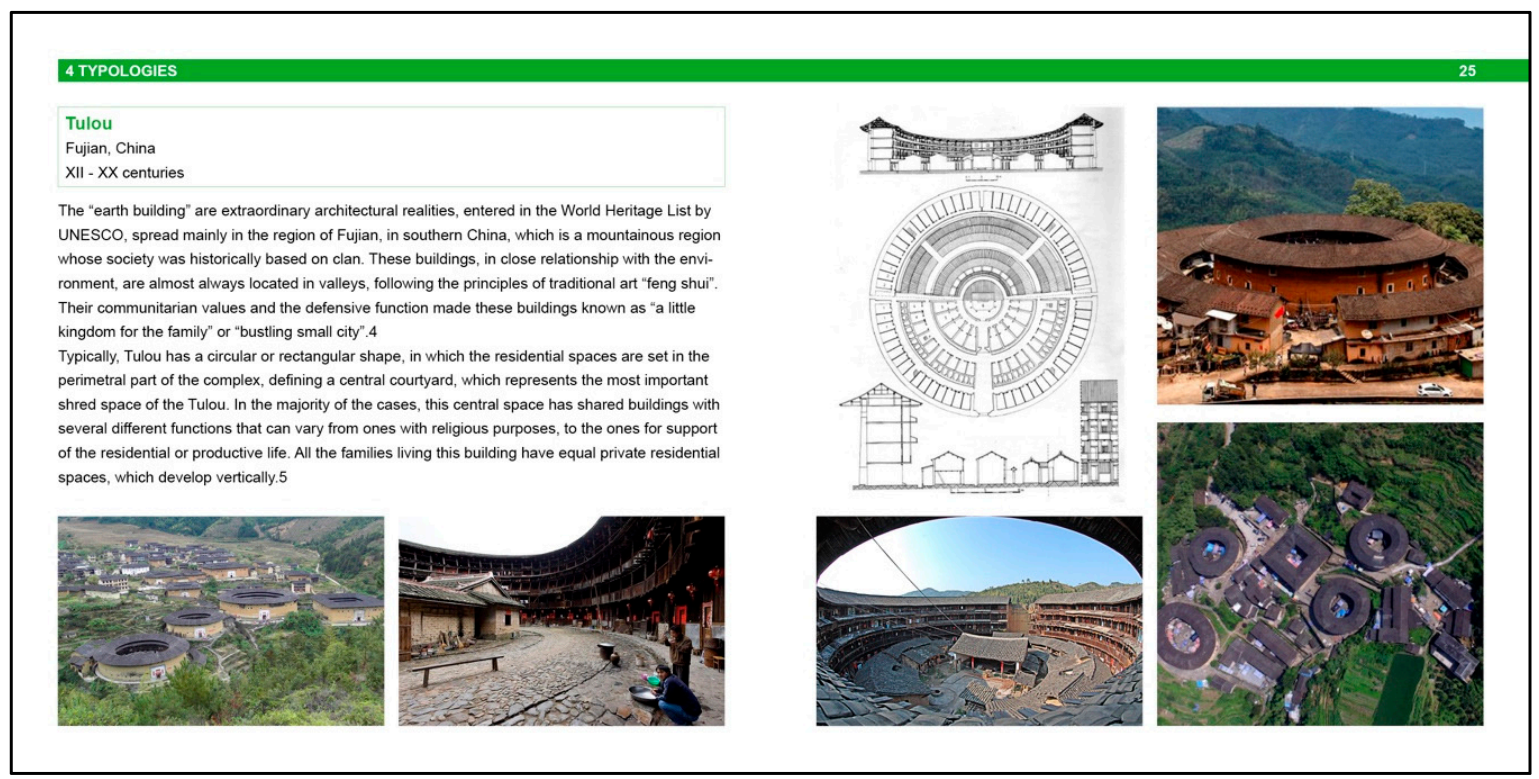

Figure 1. Pages of the booklet used during the Expert Interview to present the typology of "Tulou" to the experts.

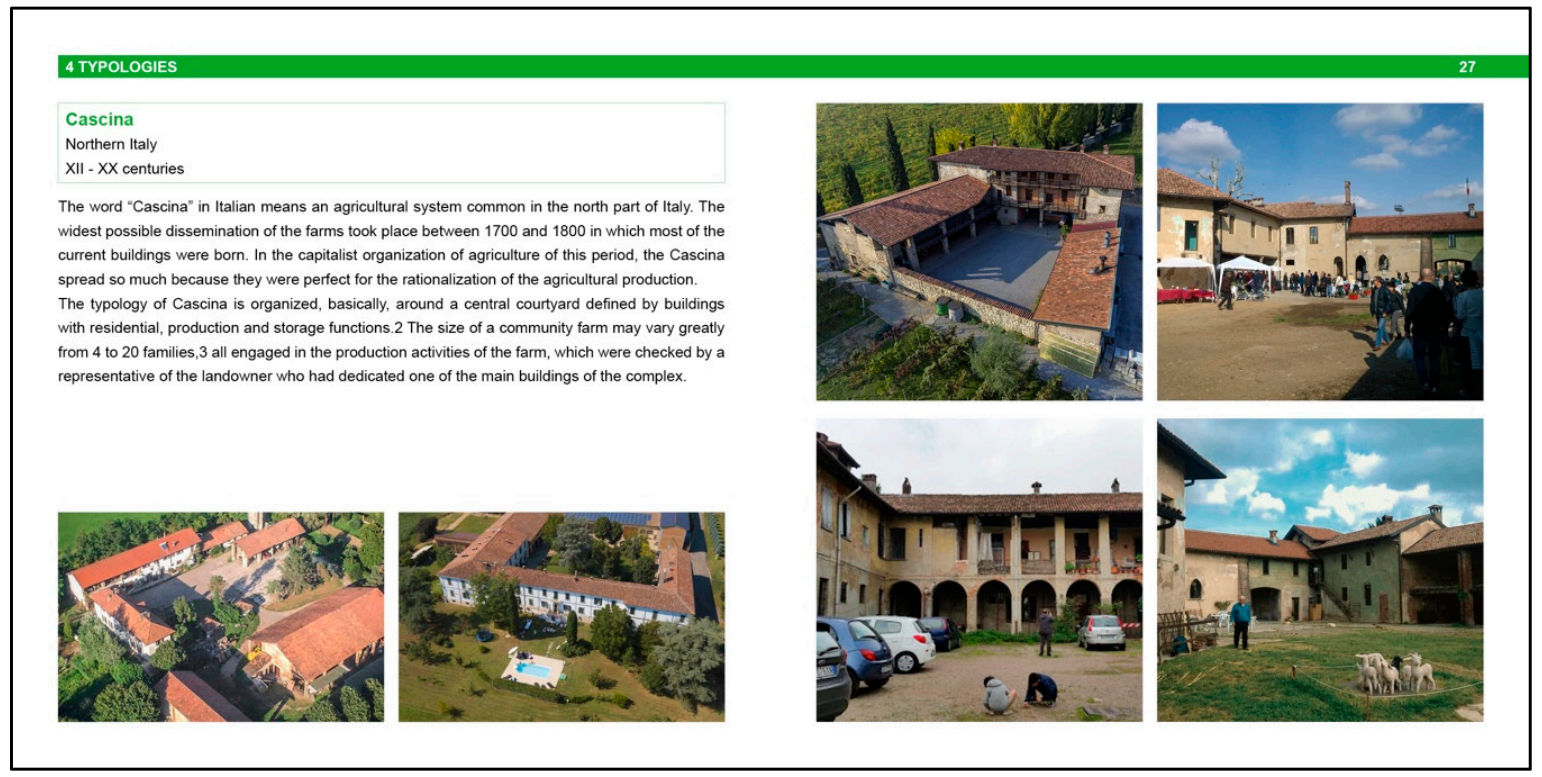

Figure 2. Pages of the booklet used during the Expert Interview to present the typology of "Cascina" to the experts. 


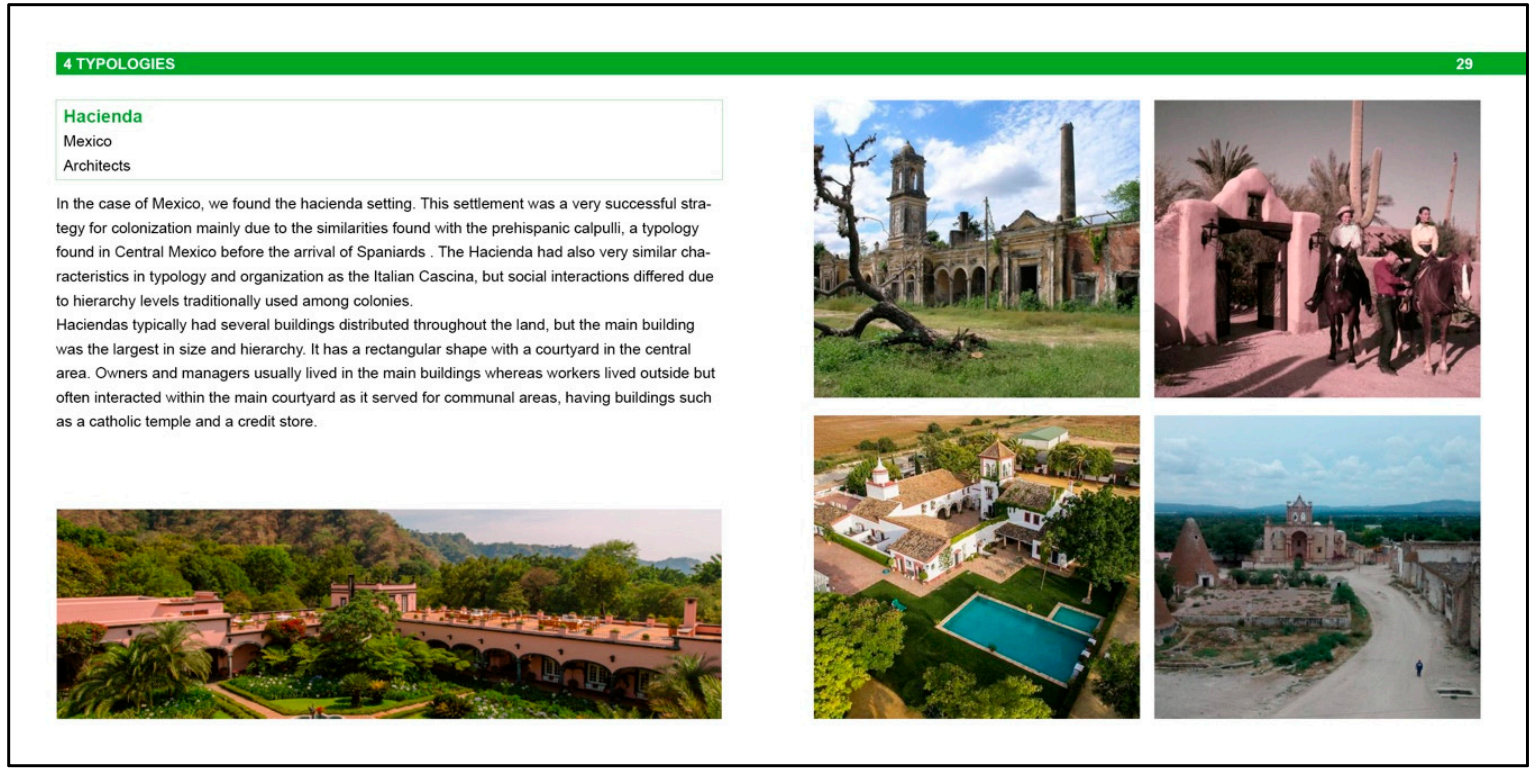

Figure 3. Pages of the booklet used during the Expert Interview to present the typology of "Hacienda" to the experts.

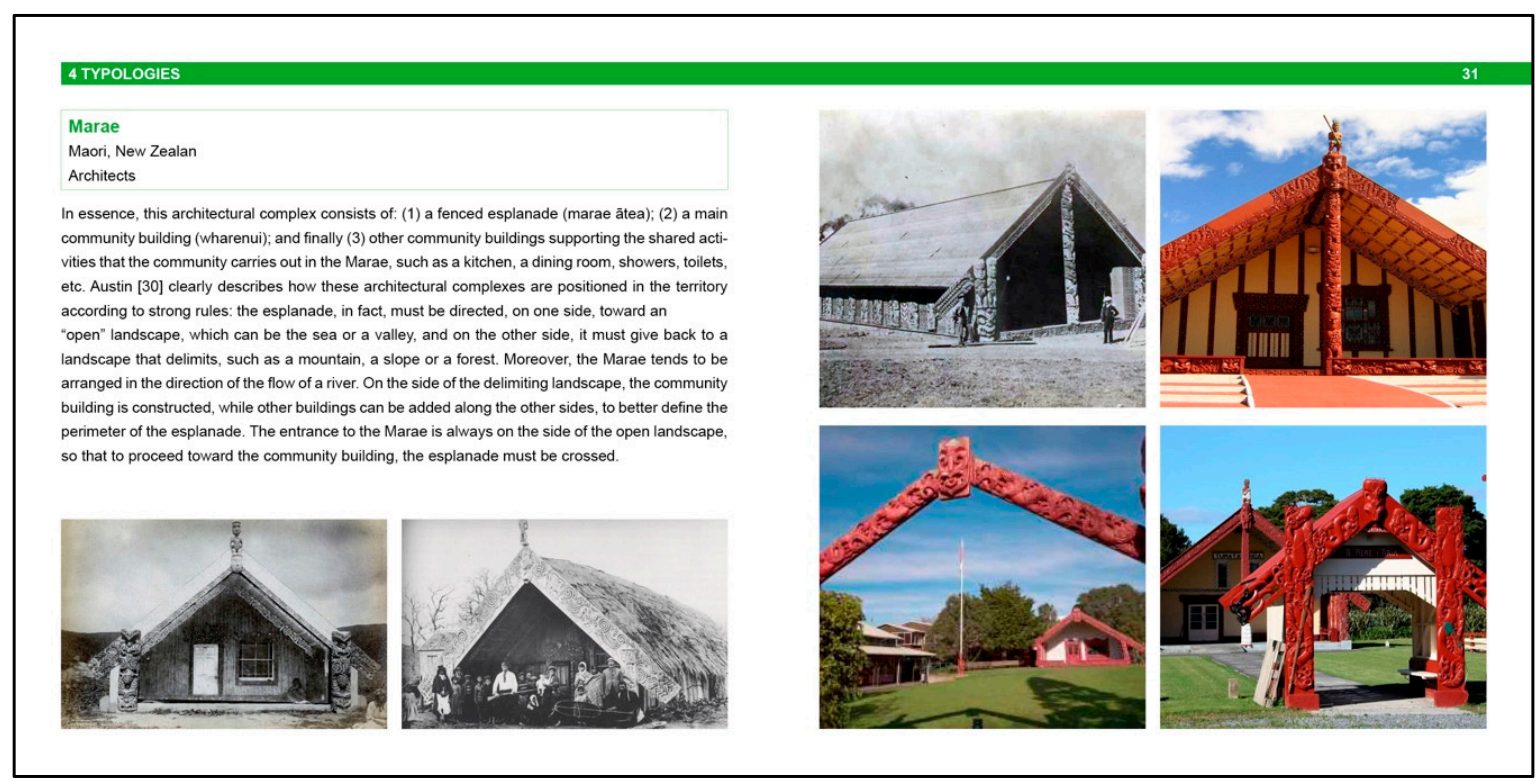

Figure 4. Pages of the booklet used during the Expert Interview to present the typology of "Marae" to the experts.

\subsection{Definition of the Regeneration Projects}

Three recently regenerated projects were selected for each typology. This decision was made considering a good balance between the need to provide a varied representation of the design approach (one or two cases per typology would not have been sufficient) and the need to have an in-depth analysis in terms of information useful for evaluating the project by the experts (a greater number of projects would have meant reducing the attention that the experts could provide analyzing the phenomena and, therefore it would have represented an incapacity to deeply analyze the projects).

Moreover, these projects have been selected from the panorama of local regeneration projects, excluding all those demolition and reconstruction of SLH that are oriented to the mere real estate market of selling houses in old-style buildings. Unfortunately, this is a contemporary tendency driven by real estate speculation, and not by the actual community and historical heritage regeneration. 
To better represent and analyze the reality, the authors preferred not to account for "striking" cases published in architecture magazines or projects considered as "best practices". On the contrary, project selection considered these aspects: (1) consistency with the local tendency, which means that the projects reflect the features of other regeneration projects of the same typology; (2) reduced antiquity of the project; (3) abundant availability of material that describes the whole characteristics of the project. The first point, although introduces some bias specific to the authors, allows at the same time to reduce the number of projects necessary for the evaluation (as explained above) and to ensure that the results of the Expert Interview are as consistent as possible with reality. So, it should be noted how this selection, because of its methodological relevance, was the result of a long and deep process of reflection and study by the authors.

A narrative description of the projects is presented in Appendix A.

\subsection{Choice of Existing Indicators to Study the Territorial Impact of Regeneration Projects}

In order to guide the analysis of the projects and to be able to evaluate them, the authors decided to provide the experts with indicators that would highlight the two main aspects on which the research focuses: (1) the sustainability of the regeneration projects of the historical heritage and (2) the sustainability of the territorial impacts that characterizes these projects. Since the research does not aim to define new indicators, if not to evaluate the impact of these regenerative processes, the authors selected from the current academic literature two sets of indicators capable to guide the analysis and the study of these projects. So, to guide the experts in the evaluation, the following two sets of indicators have been considered:

- $\quad$ sustainability of the regeneration projects of the historical heritage: Cultural Heritage Indicators (CHIs). For the indicators concerning the practice of urban-architectural regeneration, the indicators developed by F. Nocca in the article " The Role of Cultural Heritage in Sustainable Development: Multidimensional Indicators as Decision-Making Tool" [47] have been taken into consideration. These indicators, in fact, highlight the aspects that the research wants to analyze related to the historical heritage. The indicators, as presented by Nocca have been lightly modified accordingly: the impact category of "Cultural value of properties/landscape" mainly referring to the "number of well-preserved/in ruin buildings" and to the "State of conservation of heritage/landscape asset" were removed. Although the degree of preservation is central to our research, it is not significant as a variable to consider for the evaluation of experts because it was standardized through the project selection process made by the authors so that all projects could be evaluated starting from the same level of "State of conservation of heritage/landscape asset". To see the list of indicators that compose this category, please refer directly to the text of Nocca [47].

- sustainability of the territorial impacts: Sustainable Development Goals (SDGs). In order to assess the sustainability of the territorial impacts of each project, it was decided to take into consideration the SDGs that are valid internationally as a reference framework for the territorial development practices that want to reach defined sustainability objectives [48]. Based on some previous research developed by the authors [49] and for the relevance that only some goals have in territorial and social implications, it was decided to consider just some SDGs. According to the relevance of some specific SDGs for territorial and social implications, as defined by the previous studies [49,50], the SDGs presented in Figure 5 have been considered. Hence, with the research question in mind, the targets and sub-targets of the SDGs relevant to shared life and regeneration of abandonment of rural settlements as strategies for the development of sustainable territories are taken into account and described thematically in order to provide precise information to the experts for their evaluation. Thus, according to the methodology for SDGs selection designed by Henzler et al. [50], the SDGs' selection process was structured as follows: (1) SDGs analysis; (2) Selection of SDGs relevant to shared life and regeneration of abandonment of rural settlements as strategies for development of sustainable territories; (3) Thematic description of the selected SDGs categories and indicators for impact category groups. 
1- (SDG4) Quality Education

- By 2030 , ensure that all girls and boys complete free, equitable and quality primary and secondary education leading to relevant and effective learning outcomes. - By 2030 , ensure that all girls and boys have access to quality early childhood development, care and pre-primary education so that they are ready for primary education. - By 2030 , ensure equal access for all women and men to affordable and quality technical, vocational and tertiary education, including university. - By 2030 , substantially increase the number of youth and adults who have relevant skills, including technical and vocational skills, for employment, decent jobs and entrepreneurship. - By 2030 , eliminate gender disparities in education and ensure equal access to all levels of education and vocational training for the vulnerable, including persons with disabilities, indigenous peoples and children in vulnerable situations. - By 2030 , ensure that all youth and a substantial proportion of adults, both men and women, achieve literacy and numeracy. - By 2030, ensure that all learners acquire the knowledge and skills needed to promote sustainable development, including, among others, through education for sustainable development and sustainable lifestyles, human rights, gender equality, promotion of a culture of peace and nonviolence, global citizenship and appreciation of cultural diversity and of culture's contribution to sustainable development. - Build and upgrade education facilities that are child, disability and gender sensitive and provide safe, non-violent, inclusive and effective learning environments for all. - By 2020 , substantially expand globally the number of scholarships available to developing countries, in particular least developed countries, small island developing States and African countries, for enrolment in higher education, including vocational training and information and communications technology, technical, engineering and scientific programmes, in developed countries and other developing countries. - By 2030 , substantially increase the supply of qualified teachers, including through international cooperation for teacher training in developing countries, especially least developed countries and small island developing States.

\section{2-(SDG8) Decent Work and Economic Growth}

- Sustain per capita economic growth in accordance with national circumstances and, in particular, at least 7 per cent gross domestic product growth per annum in the least developed countries - Achieve higher levels of economic productivity through diversification, technological upgrading and innovation, including through a focus on high-value added and labour-intensive sectors - Promote development-oriented policies that support productive activities, decent job creation, entrepreneurship, creativity and innovation, and encourage the formalization and growth of micro-, small- and medium-sized enterprises, including through access to financial services - Improve progressively, through 2030 , global resource efficiency in consumption and production and endeavour to decouple economic growth from environmental degradation, in accordance with the 10-year framework of programmes on sustainable consumption and production, with developed countries taking the lead - By 2030 , achieve full and productive employment and decent work for all women and men, including for young people and persons with disabilities, and equal pay for work of equal value - By 2020 , substantially reduce the proportion of youth not in employment, education or training - Take immediate and effective measures to eradicate forced labour, end modern slavery and human trafficking and secure the prohibition and elimination of the worst forms of child labour, including recruitment and use of child soldiers, and by 2025 end child labour in all its forms - Protect labour rights and promote safe and secure working environments for all workers, including migrant workers, in particular women migrants, and those in precarious employment - By 2030, devise and implement policies to promote sustainable tourism that creates jobs and promotes local culture and products - Strengthen the capacity of domestic financial institutions to encourage and expand access to banking, insurance and financial services for all - Increase Aid for Trade support for developing countries, in particular least developed countries, including through the Enhanced Integrated Framework for Trade-Related Technical Assistance to Least Developed Countries - By 2020, develop and operationalize a global strategy for youth employment and implement the Global Jobs Pact of the International Labour Organization

\section{3- (SDG9) Industry, Innovation and Infrastructure}

- Develop quality, reliable, sustainable and resilient infrastructure, including regional and transborder infrastructure, to support economic development and human well-being, with a focus on affordable and equitable access for all - Promote inclusive and sustainable industrialization and, by 2030 , significantly raise industry's share of employment and gross domestic product, in line with national circumstances, and double its share in least developed countries - Increase the access of small-scale industrial and other enterprises, in particular in developing countries, to financial services, including affordable credit, and their integration into value chains and markets - By 2030 , upgrade infrastructure and retrofit industries to make them sustainable, with increased resourceuse efficiency and greater adoption of clean and environmentally sound technologies and industrial processes, with all countries taking action in accordance with their respective capabilities - Enhance scientific research, upgrade the technological capabilities of industrial sectors in all countries, in particular developing countries, including, by 2030 , encouraging innovation and substantially increasing the number of research and development workers per 1 million people and public and private research and development spending - Facilitate sustainable and resilient infrastructure development in developing countries through enhanced financial, technological and technical support to African countries, least developed countries, landlocked developing countries and small island developing States - Support domestic technology development, research and innovation in developing countries, including by ensuring a conducive policy environment for, inter alia, industrial diversification and value addition to commodities - Support domestic technology development, research and innovation in developing countries, including by ensuring a conducive policy environment for, inter alia, industrial diversification and value addition to commodities

Figure 5. Cont. 


\section{Sustainable Index (Sustainable Development Goals)}

4- (SDG10) Reduced Inequalities

- By 2030, progressively achieve and sustain income growth of the bottom 40 per cent of the population at a rate higher than the national average - By 2030, empower and promote the social, economic and political inclusion of all, irrespective of age, sex, disability, race, ethnicity, origin, religion or economic or other status - Ensure equal opportunity and reduce inequalities of outcome, including by eliminating discriminatory laws, policies and practices and promoting appropriate legislation, policies and action in this regard - Adopt policies, especially fiscal, wage and social protection policies, and progressively achieve greater equality - Improve the regulation and monitoring of global financial markets and institutions and strengthen the implementation of such regulations Ensure enhanced representation and voice for developing countries in decision-making in global international economic and financial institutions in order to deliver more effective, credible, accountable and legitimate institutions - Facilitate orderly, safe, regular and responsible migration and mobility of people, including through the implementation of planned and well-managed migration policies - Implement the principle of special and differential treatment for developing countries, in particular least developed countries, in accordance with World Trade Organization agreements - Encourage official development assistance and financial flows, including foreign direct investment, to States where the need is greatest, in particular least developed countries, African countries, small island developing States and landlocked developing countries, in accordance with their national plans and programmes - By 2030, reduce to less than 3 per cent the transaction costs of migrant remittances and eliminate remittance corridors with costs higher than 5 per cent

\section{5- (SDG11) Sustainable Cities and Communities}

- By 2030, ensure access for all to adequate, safe and affordable housing and basic services and upgrade slums - By 2030, provide access to safe, affordable, accessible and sustainable transport systems for all, improving road safety, notably by expanding public transport, with special attention to the needs of those in vulnerable situations, women, children, persons with disabilities and older persons - By 2030, enhance inclusive and sustainable urbanization and capacity for participatory, integrated and sustainable human settlement planning and management in all countries - Strengthen efforts to protect and safeguard the world's cultural and natural heritage - By 2030, significantly reduce the number of deaths and the number of people affected and substantially decrease the direct economic losses relative to global gross domestic product caused by disasters, including water-related disasters, with a focus on protecting the poor and people in vulnerable situations - By 2030 , reduce the adverse per capita environmental impact of cities, including by paying special attention to air quality and municipal and other waste management - By 2030 , provide universal access to safe, inclusive and accessible, green and public spaces, in particular for women and children, older persons and persons with disabilities - Support positive economic, social and environmental links between urban, peri-urban and rural areas by strengthening national and regional development planning - By 2020 , substantially increase the number of cities and human settlements adopting and implementing integrated policies and plans towards inclusion, resource efficiency, mitigation and adaptation to climate change, resilience to disasters, and develop and implement, in line with the Sendai Framework for Disaster Risk Reduction 2015-2030, holistic disaster risk management at all levels - Support least developed countries, including through financial and technical assistance, in building sustainable and resilient buildings utilizing local materials

\section{6- (SDG12) Responsible Consumption and Production}

- Implement the 10-year framework of programmes on sustainable consumption and production, all countries taking action, with developed countries taking the lead, taking into account the development and capabilities of developing countries - By 2030, achieve the sustainable management and efficient use of natural resources - By 2030 , halve per capita global food waste at the retail and consumer levels and reduce food losses along production and supply chains, including post-harvest losses - By 2020, achieve the environmentally sound management of chemicals and all wastes throughout their life cycle, in accordance with agreed international frameworks, and significantly reduce their release to air, water and soil in order to minimize their adverse impacts on human health and the environment - By 2030, substantially reduce waste generation through prevention, reduction, recycling and reuse - Encourage companies, especially large and transnational companies, to adopt sustainable practices and to integrate sustainability information into their reporting cycle - Promote public procurement practices that are sustainable, in accordance with national policies and priorities - By 2030 , ensure that people everywhere have the relevant information and awareness for sustainable development and lifestyles in harmony with nature - Support developing countries to strengthen their scientific and technological capacity to move towards more sustainable patterns of consumption and production - Develop and implement tools to monitor sustainable development impacts for sustainable tourism that creates jobs and promotes local culture and products - Rationalize inefficient fossilfuel subsidies that encourage wasteful consumption by removing market distortions, in accordance with national circumstances, including by restructuring taxation and phasing out those harmful subsidies, where they exist, to reflect their environmental impacts, taking fully into account the specific needs and conditions of developing countries and minimizing the possible adverse impacts on their development in a manner that protects the poor and the affected communities

\section{7- (SDG13) Climate Action}

- Strengthen resilience and adaptive capacity to climate-related hazards and natural disasters in all countries - Integrate climate change measures into national policies, strategies and planning - Improve education, awareness-raising and human and institutional capacity on climate change mitigation, adaptation, impact reduction and early warning - Implement the commitment undertaken by developed-country parties to the United Nations Framework Convention on Climate Change to a goal of mobilizing jointly $\$ 100$ billion annually by 2020 from all sources to address the needs of developing countries in the context of meaningful mitigation actions and transparency on implementation and fully operationalize the Green Climate Fund through its capitalization as soon as possible Promote mechanisms for raising capacity for effective climate change-related planning and management in least developed countries and small island developing States, including focusing on women, youth and local and marginalized communities

Figure 5. Graphical resume of the seven Sustainable Development Goals (SDGs) taken into account for the Expert Interview.

Both the sets of indicators are presented in the following Figures 5 and 6. 


\begin{abstract}
1- Tourism and Recreation
(1) Touristic demand (2) Touristic supply (3) Economic vitality (4) Economic impact on local wealth

Tourism, defined as "a social, cultural and economic phenomenon related to the movement of people to places outside their usual place of residence, pleasure being the usual motivation", but also for other reasons "such as leisure, business, religious or health reasons and other purposes such as visiting friends and relatives", according to the International Recommendations for Tourism Statistics 2008 , has become a pillar of economies, "a passport to prosperity". It is a sector that is able to transform cultural values into economic ones.
\end{abstract}

2- Creative, cultural and innovative activities

(1) Cultural demand; (2) Cultural supply; (3) Economic vitality; (4) Economic impact on local wealth; (5) Employment in cultural activities

There is a double relationship between the tourism sector and climate change: the tourism sector is contemporaneously both "a vector and a victim" of climate change (UNWTO Secretary-General, Taleb Rifai). The tourism sector cannot be excluded from the challenge to the global climate change; so, its impacts on climate change (that to date are underestimated) have to be considered, without forgetting the close relationship between tourism and global warming.

\title{
3- Typical local productions
}

(1) Creative firms; (2) Local production; (3) Employment in local production

Local production (craft and traditional products), as part of cultural heritage, is able to enhance local identity, too. Local specialties representing local identity, are able to impart values of the community: identity values of the territory are expressed also through typical local products, when considering the strong link between the product and its place of origin. Companies, in particular smaller size ones, see in the typical products a chance to find a new competitive space against increasingly competitive markets by price.

\section{4- Environment and natural capital}

(1) Environmental preservation; (2) Green areas and facilities supply

Although the negative impacts (related to the double relationship between cultural heritage/cultural tourism and climate change) highlighted in the previous paragraph, the integrated conservation is able to produce also environmental benefits. The indicators related to this category rarely emerge from the analysis of the case studies: only three indicators (out of 177 referred to the 9 categories) in three case studies out of forty.

\section{5- Social capital/cohesion and inclusion}

(1) Social cohesion; (2) Sharing/collaborative economy initiatives; (3) Employment; (4) Social inclusion

Climate change can have negative impacts on integrity and authenticity of cultural heritage, damaging, and depriving the community of its "symbols". This is both physical and intangible deprivation. This draws also the attention to issues related to the enhancement of the local community, in addition to tourism and real estate issues. In this perspective, indicators related to the state of conservation of cultural heritage and the enhancement of local community (social cohesion and civic conscience) have to be considered.

\section{6- Real estate and Financial return}

(1) Real estate value; (2) Real estate supply; (3) Real estate development; (4) Public financial return

Real estate is positively influenced by investments in cultural heritage: the project areas and the surrounding areas usually revealed an increase in real estate value. Sometimes this increase can have negative impacts, such as gentrification phenomenon (interpreted as expulsion of the most vulnerable part of the population both in economic terms and cultural ones): local community and young people can no longer afford to buy/rent apartments because of rising prices; therefore, as has emerged from some case studies, many apartments remain unused for many years and the owners do not care about maintenance, causing the deterioration of them. Furthermore, the increase in property value produces a "touch and go" tourism because of the high prices to stay in the area object of intervention.

\section{7- Cultural value of properties / landscape}

(1) State of conservation of heritage/landscape asset

Cultural heritage expresses and maintains values and traditions of a city and its community, but its significance can be different among communities and also among members of the same community. It links past, present, and future but, at the same time, it has the potential for conflicts. Diverse social groups could have different values and beliefs, with different perceptions about what is relevant for their identity, attributing different values to a heritage place. The coexistence of these differences can represent a problematic issue and sometimes can be the cause of actions that could have negative impacts on heritage values.

\section{8- Wellbeing}

(1) Security; (2) Quality of services; (3) Housing quality; (4) Health

Mere economic indicators, as those referred to in the above-mentioned financial category, leave out many aspects that are not economically evaluable. They are able to evaluate the economic growth, but they do not represent people wellbeing. They alone are not significant because they are not able to capture information about wellbeing, happiness and the level of the life quality of citizens: it needs to go beyond the mere economic numbers. Economics should be only instrumental to the achievement of wellbeing.

Figure 6. Graphical resume of the eight Cultural Heritage Indicators (CHI) taken into account for the Expert Interview, as presented in the booklet.

\subsection{Expert Interview to Evaluate the Projects}

Once typologies were defined, projects were selected and the appropriate sets of indicators identified, the actual organization of the Expert Interview was carried out. In agreement with what emerged in the study of academic literature on the subject (already introduced at the beginning of 
this section) and with the aim of reaching a phase of fruitful discussion with the experts, the authors worked in defining two aspects: choosing the correct experts and creating the material to be provided to the experts to guide the activity.

\subsubsection{Experts and Material Definition}

Guided by the seminal book of Bogner, Litting, and Menz [38], it was possible to determine the required number, and as well as to make the right choice of experts.

They were selected from professionals, academics, and non-academics, whose work in the fields of territorial sustainability and regeneration of the built heritage was well recognized. According to comparisons with other research and considering the differences among the "four contexts", the number of experts needed for this activity was set at 11 . The names and short background of the experts are included in Appendix B.

Moreover, the authors took care that the experts (1) came from the four studied geographic areas and (2) that they had a cultural knowledge of at least two cultures of each typology and as well as a basic knowledge of the four cultures under investigation, (3) they have not only academic knowledge but are active in community affairs of the context under investigation regardless of their position [38]. The reason was that their mixed expertise (as both an academic and active person in the context) can be considered socially institutionalized-as defined earlier-and linked to a specific context, even though in a different way from the expertise fully grounded on the academic role. This was the case for instance of Expert number 04, 06, 08, 09, and 11.

The initial phase of screening for the selection of a pool of potential experts had been done on the basis of the authors' academic network. By keeping in mind the three basic characteristics of the experts as earlier mentioned, we immediately realized potential limitations for the application of this methodology. In fact, we had found two possible groups of experts for which this difference might have affected the assessments; namely, in some cases, the careers of some scholars were not yet long enough to be considered extraordinary in terms of research abilities, though there was already evidence of some results achieved. This was the example of Expert number 07 and 10. Of course, the opposite case has also occurred, for example of high-level scholars who had made outstanding careers in the past but had concluded their activities because of retirement. This was the case of Expert number 03, 05, and 06. Nevertheless, for our objectives, some kinds of abilities are more important than the current research performance that can offer a distorted picture of the relevant knowledge of one expert.

Hence, given these numerous problems that could have led to an improper selection of experts, we used two main elements before to complete the expert selection as suggested again by Bogner, Litting, and Menz [38]:

- Collecting standard discipline-scientific information about the scholars such as publications, citations, awards, memberships, and institutional and non-institutional engagement. These were all downloadable from Internet pages, the Web of Science, and other databases.

- Supplementing the previous standard information with "other" kinds of information from the experts, such as for example, other research interests, public engagement, activism in association (i.e., ONG), members of citizens' groups, as well as volunteers in welfare, social work, and similar fields.

In the final phase, crosschecking all these data and screening, a pool of potential experts had been listed. Thus, each expert was contacted directly to confirm the willingness to participate. From this last operation, the final pool of experts has been designated in Appendix B.

In brief, the eleven experts represent a mixed group of insiders and outsiders with regards to the four contexts studied. Moreover, they are divided into high ranked scholars in their field of studies and young researchers with evidence of some results already achieved such as Expert number 07, 10, and 11. On the other hand, the expert group is composed of young scholars that are also active in community affairs of the context and senior scholars with a background of social volunteering and/or 
managerial direction of associations or public offices, such as for example the Experts number 04 and 08 and the Expert number 03, 05, and 06, respectively.

At the end of this delicate process, we can affirm that the final pool of the eleven selected experts was well balanced with regard to the above characteristics and quality as required for the experts' attributes in the scientific literature.

Meanwhile, as for the creation of the materials to be provided to the experts, a 60-page booklet was created collecting all the material necessary to carry out the activity. This booklet, which is not presented here for obvious reasons of spatial limitations, is available to everyone, at the following link (https://www.dropbox.com/s/tp6tuhetr9u8r8z/Expert\%20Interview_booklet.pdf?dl=0) [46].

In the development of this article, however, various references are made to the contents of the booklet and some pages are presented as a template to show it as much as possible. This booklet is divided into four parts which present respectively: (1) objectives and methodology of the activity; (2) indicators to be used; (3) historical typologies; (4) projects to be analyzed.

- objectives and methodology of the activity: This section includes an introduction to the research rationale, the purpose of the expert's involvement, and the ways in which the research will be followed;

- indicators to be used: This section introduces both schematic and discursive presentation of the indicators selected to guide the evaluation of the experts. In addition to the indicators punctually explained, bibliographic references are provided for voluntary insights.

- historical typologies: In this section, each typology is presented through a textual description made by the authors. The goal is to make the experts confident with the typologies, also through various pictures and bibliographical references.

- projects to be analyzed: In this section, each project is presented through a text prepared by the authors (annex A), some links (i.e., to the architects' web page) for detailed study, and some pictures.

Besides the booklet, experts received instructions on the next steps to be implemented. It is pleonastic to highlight that all the experts have already proved knowledge on this matter.

\subsubsection{Expert Interview Operating Method}

Once the Experts' list was defined and the material sent to them, the authors decided to operate according to the following phases:

1. Site survey and first round of meetings: Site survey for the introduction to research and presentation of cases had been organized in September 2019 and January 2019 in China, Shanghai, and Milan, Italy, respectively. Authors and their research teams traveled and surveyed together numerous projects in China and in Lombardy, Italy, while another two field trips in Mexico and New Zealand were planned. Unfortunately, these last two field trips were not possible due to the COVID-19 pandemic outbreak, thus the local research teams completed this phase of the investigation. Regarding the experts' involvement despite the new circumstances generated by the pandemic and the differences in the geographical time-zone areas of the experts, telematic meetings were held using the Zoom platform. During these first meetings, the authors introduced the research to the experts, describing its objectives and methods, and presented the projects to avoid misunderstanding and to answer eventual questions. From these first meetings, some questions and considerations emerged, so to help the authors redefine the final questions, to which the experts would be asked to answer later. Some main considerations the experts shared were regarding the importance of the local context and the role of the local governments as well as the relevant differences among the four realities.

2. Refinement of the questionnaire to be submitted to the experts: based on the observations that emerged, the authors refined the questions to be submitted to the interview of experts. 
3. Second round of meetings and Expert Interview: once the questions were completed on the basis of the experts' first observations, the final questionnaires were sent. For two weeks, the experts expressed their opinions supported by the questionnaire or during one-on-one meetings with the authors, who collected the answers within the same questionnaire. Due to differences in countries, the questionnaire was supported by a Google Form and by an Excel file. The answers were finally collected in a unique file that allowed the analysis and the development of the final results.

To summarize the whole process a figure of the flow of the activities carried out by the authors is illustrated in a simplified manner in Figure 7.

\begin{tabular}{|c|c|c|c|c|c|}
\hline \multirow[b]{2}{*}{$\frac{n}{\frac{0}{m}}$} & 1 & 2 & 3 & 4 & 5 \\
\hline & $\begin{array}{c}\text { Survey, organizing } \\
\text { meeting } \\
\text { and material }\end{array}$ & $\begin{array}{l}\text { First round of } \\
\text { meetings with } \\
\text { Experts }\end{array}$ & $\begin{array}{l}\text { Refinement of the } \\
\text { questionnaire }\end{array}$ & $\begin{array}{l}\text { Second round } \\
\text { of meetings and } \\
\text { Expert Interview }\end{array}$ & Results \\
\hline 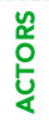 & $\begin{array}{c}\text { Authors } \\
+ \\
\text { Research Teams }\end{array}$ & $\begin{array}{c}\text { Authors } \\
+ \\
\text { All Experts }\end{array}$ & Authors & $\begin{array}{c}1 \text { to } 1 \\
\text { Author + Expert }\end{array}$ & Authors \\
\hline $\begin{array}{l}\sum^{4} \\
\text { U⿺ } \\
\\
0\end{array}$ & $\begin{array}{l}\text { Site Visit (where posible) } \\
\text { Literature Review } \\
\text { Booklet } \\
\text { and Questionnaire }\end{array}$ & $\begin{array}{c}\text { Questionnaire } \\
\downarrow \\
\text { Discussion } \\
\text { and Observations }\end{array}$ & $\begin{array}{c}\text { Observations } \\
\text { Final Questionnaire } \\
\text { and Interview }\end{array}$ & $\begin{array}{c}\text { Interview } \\
\downarrow \\
\text { Results }\end{array}$ & $\begin{array}{l}\text { Results } \\
\downarrow \\
\text { Discussions } \\
\text { and Conclusions }\end{array}$ \\
\hline
\end{tabular}

Figure 7. Workflow of the activities carried out by the authors and their research teams.

\section{Results}

The results presented here are grouped in tables, as average values of the experts' answers. All the answers from the experts are available in Appendix $C$.

Tables 1 and 2 represent the average obtained by each typology, with reference to the chosen indicators sets: selected SDGs (Table 1) and CHIs (Table 2). The authors asked the experts to evaluate according to a scale from 0 to 5 , where 0 means that the characteristic specified by the indicator is totally absent and where 5 means that the indicator fully represents the characteristics of the project.

The results will be discussed in detail later, with the support of graphical representation. However, from these tables, it is already possible to clearly highlight the attitude, common to all the four typologies, to be considered as a sustainable practice, even if the Hacienda's regenerative projects showed some delays compared to Tulou and Cascina.

Table 1. Results of the Expert Interview, associating the regeneration projects of SLH with the SDGs.

\begin{tabular}{lcccc}
\hline & Tulou & Cascina & Hacienda & Marae \\
\hline SDG 4. Quality Education & 4.2 & 3.1 & 2.3 & 3.1 \\
SDG 8. Decent Work and Economic Growth & 3.2 & 3.5 & 3.2 & 2.9 \\
SDG 9. Industry, Innovation, and Infrastructure & 2.7 & 2.9 & 2.5 & 2.6 \\
SDG 10. Reducing Inequality & 4.1 & 3.2 & 2.2 & 3.4 \\
SDG 11. Sustainable Cities and Communities & 4.2 & 3.9 & 2.8 & 3.4 \\
SDG 12. Responsible Consumption and Production & 3.3 & 3.5 & 2.7 & 3.2 \\
SDG 13. Climate Action & 2.5 & 2.9 & 2.8 & 2.8 \\
\multicolumn{1}{c}{ AVERAGE } & 3.4 & $\mathbf{3 . 3}$ & $\mathbf{2 . 6}$ & $\mathbf{3 . 0}$ \\
\hline
\end{tabular}


Table 2. Results of the Expert Interview, associating the regeneration projects of SLH with the CHIs.

\begin{tabular}{|c|c|c|c|c|}
\hline & Tulou & Cascina & Hacienda & Marae \\
\hline 1. Tourism and Recreation & 3.0 & 3.5 & 4.6 & 3.2 \\
\hline 2. Creative, cultural and innovative activities & 4.1 & 3.8 & 3.3 & 3.8 \\
\hline 3. Typical local productions & 3.2 & 3.8 & 3.0 & 3.2 \\
\hline 4. Environment and natural capital & 3.2 & 3.7 & 3.7 & 3.4 \\
\hline 5. Social capital/cohesion and inclusion & 4.6 & 4.2 & 2.5 & 4.0 \\
\hline 6. Real estate & 2.3 & 4.1 & 4.0 & 3.4 \\
\hline 7. Financial return & 4.1 & 3.5 & 3.7 & 3.5 \\
\hline 8. Wellbeing & 3.9 & 4.0 & 3.8 & 3.5 \\
\hline AVERAGE & 3.5 & 3.8 & 3.6 & 3.5 \\
\hline
\end{tabular}

With reference to the first data, it can be seen that the average valuation referring to the CHIs is much more uniform than those referring to the SDGs, even if some indicators move from this tendency: very low values emerge for the Chinese Real Estate. At the same time, very low values emerge for the Social Capital/cohesion and inclusion for the Mexican Hacienda.

By combining the four typologies in this table (Table 3), it appeared that the CHIs indicators had higher values and rarely deviate from the average. On the contrary, SDGs have differences in values and average values. Namely SDG 9 and SDG13 achieved the lowest values, SDG 11 the highest, and the SDG4, SDG8, SDG10, SDG12 did not deviate as much from the average nor from the disaggregated values. This preliminary observation of these simplified values was significant because it indicated which CHIs indicators and which SDGs the four regeneration projects contributed to more. Regarding the Cultural Heritage Indicators (CHI), it was interesting and also comforting to see the regeneration projects were more effective in terms of creative, cultural, and innovative activities (indicator 2), social capital/cohesion (indicator 5), and wellbeing (indicator 8). This was the same for the SDGs values, as they reveal that the SDG11 Sustainable Cities and Communities was the goal on which the regeneration projects contributed more to the four typologies. On the contrary, it was necessary to underline that the SDG9 Industry, Innovation and Infrastructure, and SDG13 Climate Action, were the two goals with the lowest values. This was due to the fact that in rural areas industry, innovation, and infrastructure along with climate actions were not yet fully considered central in the whole process of regeneration. It could be determined also by the fact that infrastructures, innovation as well as climate change actions are seen as in charge to the central government due to many reasons such as, for instance, the huge investments needed for infrastructural projects. This insight is already a preliminary validation of the need to define normative and superordinate design actions for sustainable development of territories (key design decisions) as it is discussed in the next section.

Table 3. Results of the Expert Interview, resuming the results for the CHIs and the SDGs indicators. In grey color are the results of the indicators that had reach the higher values.

\begin{tabular}{|c|c|c|c|c|c|c|c|c|c|c|c|c|c|c|c|}
\hline & \multicolumn{8}{|c|}{$\mathrm{CHI}$} & \multicolumn{7}{|c|}{ SDGs } \\
\hline & 1 & 2 & 3 & 4 & 5 & 6 & 7 & 8 & 4 & 8 & 9 & 10 & 11 & 12 & 13 \\
\hline Average indexes & 3.6 & 3.8 & 3.3 & 3.5 & 3.8 & 3.5 & 3.7 & 3.8 & 3.1 & 3.2 & 2.7 & 3.2 & 3.6 & 3.2 & 2.8 \\
\hline Average categories & \multicolumn{8}{|c|}{3.6} & \multicolumn{7}{|c|}{3.1} \\
\hline Total average & \multicolumn{15}{|c|}{3.4} \\
\hline
\end{tabular}

\subsection{Graphical Representation of the Results}

In order to highlight the aspects considered, the results of the Expert Interviews were represented in diagrams. Representations based on two types of diagrams have been chosen:

- Cartesian diagram-individual projects located in a Cartesian plan defined by the dimensions of sustainability (SDGs) and regenerative approach (CHIs). Each project finds its place in the plan 
thanks to the coordinates given by the average values obtained in the Expert Interview for the categories of SDGs and CHIs. Additionally, the projects of each typology have been represented with the same color, so to allow to underline the behavior of the four typologies. Moreover, lines connect the points of the three projects, so to create an area, which will allow the authors to find additional characteristics and behaviors for each typology. This chart allows an overview of the performances of each project and typology related to their impacts on territories, in terms of sustainable development and regenerative approach.

- Radar-the behavior of the four regenerated SLH typologies are represented on the basis of the values they reached for the two sets of indicators. Two diagrams have been created: one for the CHIs indicators and one for the SDGs. Unlike the previous diagram, both of these charts allow for highlighting the most important typology behaviors with respect to the single indicators, thus arriving at more detailed and deep observations.

\subsubsection{Relation among Projects, Typologies, SDGs and CHI}

This Cartesian Diagram shows the results of the four different typologies, highlighting how each one has its own characteristics in terms of territorial effects. The different arrangements in the plan and some common characteristics among the typologies allowed us to propose some relevant observations. By analyzing the diagram, for each typology can be highlighted in the following aspects:

- Tulou (green): the three projects had limited difference in terms of results, highlighting that the regeneration projects of this type were clearly thought out according to the effects they must produce in the area.

- Cascina (blue): similar to the Tulou projects, even those of the farmhouses had a fairly limited difference in terms of territorial results. This can be dictated by the fact that these projects usually have a fairly common goal or are limited by the characteristics of local regulations.

- Hacienda (yellow): it was evident that two of the three projects have fairly low evaluations with reference to the SDGs. In particular, for some characteristics of projects that were mainly aimed at the private sector, no benefits of sustainable impact for the territory were highlighted.

- Marae (red): even in the case of the Marae, the three projects were positioned quite far from each other, showing how the impacts on the territory were of different elements still alive in today's New Zealand society (it meant that the impacts they have on the territory can vary a lot).

In general, from the areas as they are presented in Figure 8 are defined by the connected points of each project per typology, we can read two main tendencies namely clustered tendencies, and spread tendencies:

- clustered (Tulou and Cascina): the differences between the results were quite limited. This can be dictated by the fact that the projects were designed with a similar objective in terms of territorial impact and that in Italy and China there are quite restricted regulations or design codes that force the projects to have similar and basically good results.

- $\quad$ spread (Hacienda and Marae): the variety of results between the projects depended on the fact that the buildings take on more varied functions so that they had different effects on the territory.

These tendencies showed how the regeneration projects of Tulou and Cascina had general common effects on sustainable territorial development. In these cases, the projects gave rise to fairly homogeneous (and sustainable) territorial effects. It would be interesting to analyze, in the subsequent development of the research to what factor this trend is due to the Italian legislative restrictions in terms of regeneration of the patrimony or to the strong Chinese government control.

On the contrary, the projects of Marae and Hacienda, with a wider area among the projects, presented a more varied effect on the territories, with results that were definitely less sustainable than Tulou and Cascina. 


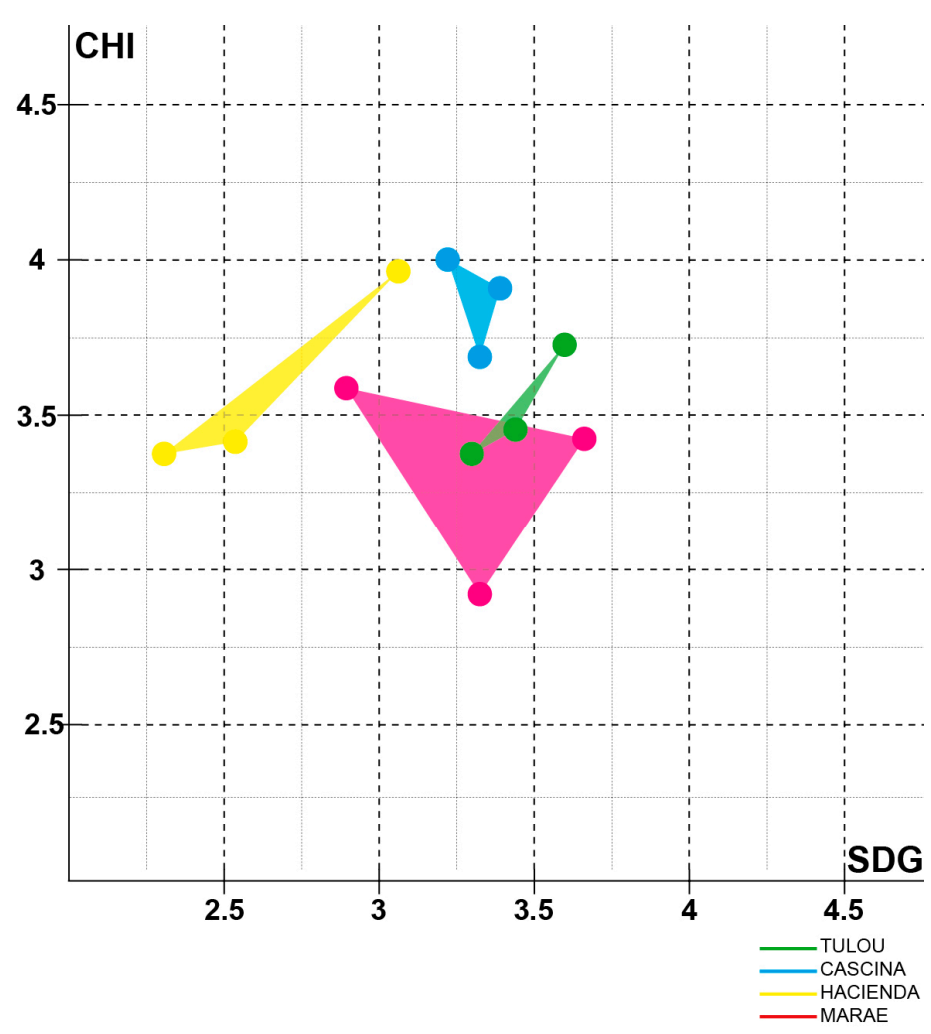

Figure 8. Territorial Impacts of the different typologies (Tulou is green; Cascina is blue; Hacienda is yellow; Marae is red) located in a diagram defined by the Sustainable Development Goals (SDGs) and the Cultural Heritage Indicators (CHIs).

\subsubsection{Relation among Typologies, and Single Indicators of SDGs and CHI}

The results presented in this following Figure 9 are the averages of each typology, with the eight CHIs parameters and the seven SDGs taken into consideration. These radar charts allowed us to visually highlight some of the tendencies and characteristics of the regeneration projects for each typology. The most significant results are discussed below.
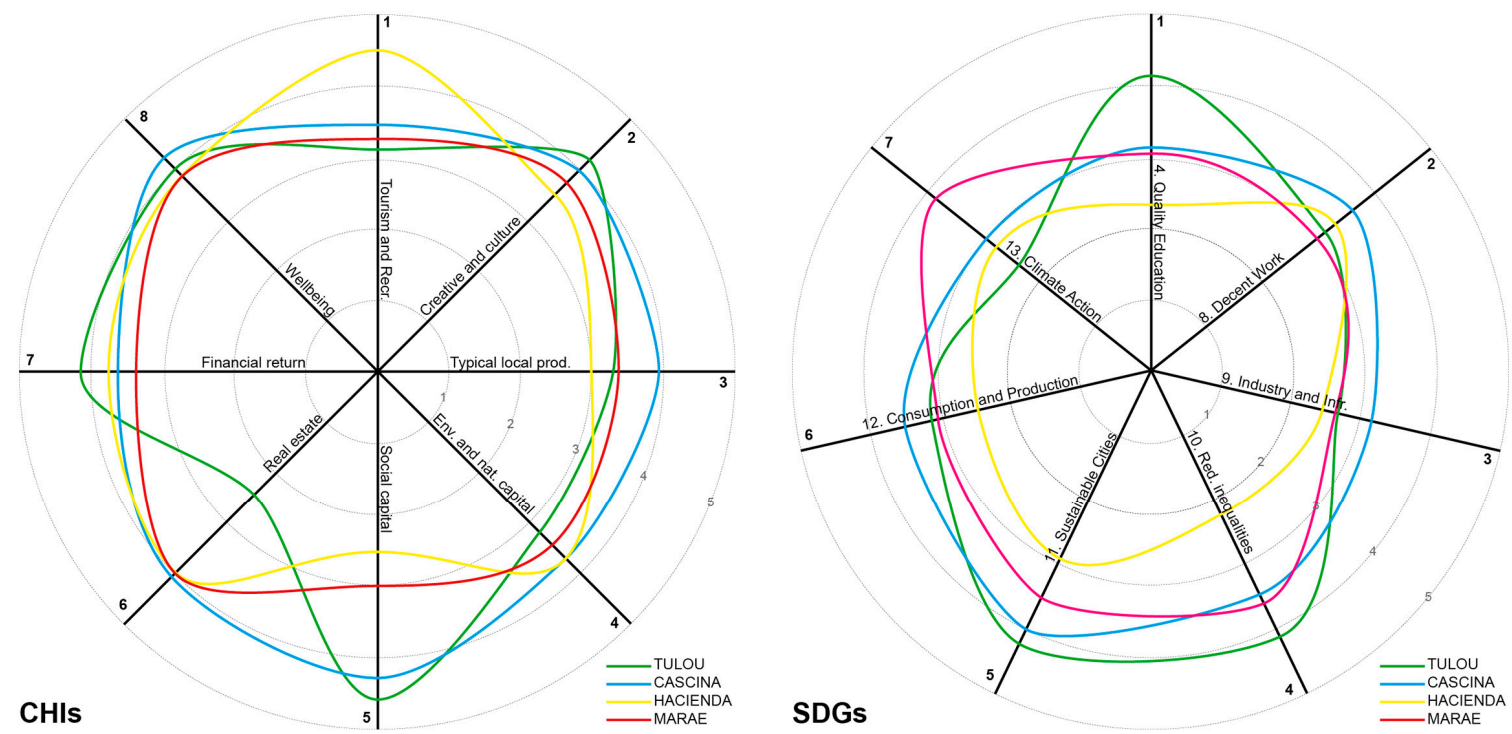

Figure 9. This figure represents results of the Experts Interview, expressed by radars, associating the projects of the four typologies to the CHIs (left) and the SDGs (right). 
Observing the Cultural Heritage Indicators (CHI) radar, it can be highlighted that, in general, the typologies had relatively uniform behaviors. In fact, the lines overlapped for most of the circle. However, precisely this overlapping highlighted some relevant aspects. While Tulou (green), Cascina (blue), and Marae (red) had relatively low values for the first indicator of Tourism and Recreational Activities, the Hacienda (yellow) regeneration projects showed a clearly higher value, showing how the tourism sector was a strong impetus of regeneration in the Mexican context. On the contrary, it emerged quite visibly from the $\mathrm{CHI}$ radar that, at the same time, Hacienda and Marae show limited impact in terms of $\mathrm{CHI}$ indicator 5 "social capital". For the Hacienda, this aspect clearly confirmed how the impact of tourism in the social sector was still problematic and a not fully resolved issue. On the other hand, this low value for the Marae, which traditionally represented the symbol of the community itself, represented how, according to the experts, contemporary regeneration projects of Marae buildings have partially lost the ability to positively impact on social capital. This value indicated that both Haciendas and Maraes communities should implement social cohesion along with collaborative economy initiatives in order to improve their social capital in terms of physical and intangible capitals. Yet, this value was, at least, less impactful than the regeneration projects of the Cascina and Tulou.

Another specific aspect that emerged from the CHI radar was the indicator 6, "Real Estate", which was very irrelevant in the Tulou projects. This aspect can undoubtedly be related to the Chinese reality, where these kinds of projects are mainly managed and promoted by the government, who considers these interventions as opportunities to compensate the local population for the heavy influence that rural and urban development is impacting territories and societies.

There is, moreover, an interesting characteristic that deserves to be underlined for the regeneration projects of Cascina (blue). CHI indicator 3, which was related to Typical Local Production, highlighted how these projects were often indeed related to the initiatives for the production of goods and services, in total alignment with the original functions of the Cascina typology, and with the orientation provided by EU priorities through rural development programs.

On the other side, if we focus on the Sustainable Development Goals (SDG) radar, the situation was a little more multifaceted and could be immediately perceived by the separation between the four lines of typologies, which were more outdistanced than the CHIs lines. In the SDGs diagram, it emerged immediately that the yellow line of the Hacienda projects was almost always the most central line. That means it was the one that showed the least values for the SDGs, representing low sustainable impacts on the territories. In particular, this was evident for Goal 10-Reduced Inequalities (Indicator 4), which also refers to the aspect highlighted in the previous diagram of CHIs for indicator 5, Social Capital. This does not mean that the regeneration projects of Haciendas are not sustainable as a whole but it means that the efficiency in terms of social sustainability for the Hacienda regeneration projects needs to be implemented in terms of ability to positively impact on social capital.

Another relevant result showed in the SDGs radar was that the Cascina (blue) and Tulou (green) regeneration projects tend to show the best values, placing themselves almost always among the outermost lines. It is interesting to relate this observation with those coming from the CHIs' diagram: the projects of Cascina and Tulou had, respectively, similar outputs in terms of territorial impacts, and both had good results in terms of sustainable impacts, albeit the great existing economical, social, and governmental differences [51].

As for Marae (red), it had behavior quite similar to that of Cascina and Tulou, showing quite positive values in terms of sustainable impacts. However, it is interesting to highlight how the attitude of the Marae regeneration projects stands out regarding Goal 13-Climate Action (Indicator 7). This issue is very intriguing and opens up interesting reflections for future research, because the Marae, as a typology, is based on a strong relationship with the environment: the orientation towards orography and natural resources are the basis of this typology which, although rigid in its spatial organization, knows how to adapt very well to the natural context. It would be interesting, in fact, to study whether this traditional characteristic can influence even the contemporary regeneration projects so deeply that this feature can appear today as a positive impact on the territory, in terms of climate action. Moreover, 
next to this consideration, the attention of New Zealand regulations in terms of climate action can be considered as a relevant aspect.

\section{Discussion and Conclusions}

The research highlights several aspects that should be discussed, both in terms of methodology and contents.

In terms of methodology, this study offers numerous confirmations that the application of the Expert Interview methodology works well with this project. For instance, the validation of phenomena emerges in the well-known problematic relationship between tourism and social impact, and the role of the Chinese government in controlling regeneration initiatives among many others as earlier described. Furthermore, the scope of application for the expert interview method is much broader and deeper than many other research procedures. Even though it has been applied in several fields of studies, it has seldom been applied in architectural and urban studies research. Hence, with this paper, it is possible to affirm that this methodology can be fruitfully used as a self-sufficient method as well as in the architectural-urban studies with the aim to analyze and interpret contemporary phenomena of various territories. For example, it can be applied for the study of and to understand how the regeneration of ancient community buildings impact the sustainable development of the local context in terms of culture and identity. This method is effective in our research because it allowed collecting unknown and/or more reliable information/insight not so evident during our investigation. As to say, significant results can be achieved when authoritative opinions and professional estimations relating to the research are taken from persons whose competence is proved and not questioned. Due to the fact that respondents in the expert interviews are highly qualified in the investigated area, it often eliminates the need for additional verification procedures.

As Meuser, Nagel, and Libakova, and Sertakova [37,39] affirmed, the application of the expert interviews allows access to information that gives an opportunity to create a holistic view of the significance of SGDs and CHIs impact on the process of regeneration territories and shared-living buildings heritage.

In terms of content and related to the research question, this study reveals that the regeneration of historic community buildings often brings a change in the relationship with the context. From the state of introversion toward the landscape of these historical buildings, the regenerated buildings become extroverts, generators of social relationships, promoters of activities, and local life; in other words, sustainable regeneration of heritage allows to re-create a community. Thanks to these changes, this research shows how the urban-architectural regeneration of these historical typologies can be clearly associated with indications of sustainable development. In fact, these projects can be related to indicators of sustainable development for the territory, but in particular with the enhancement of architectural heritage. Of course, it is necessary to underline once more that there are differences between typologies. Some show more sustainable impact than others and some show more uniformity in the results. This opens up some more questions: the fact that some typologies i.e., Cascina and Tulou can be considered as "best practices" is due to the drivers of the context such as local laws, market, cultural sensibility, or characteristics typical of the typology? For Cascina and Tulou, does the fact that uniformity of results is associated with more sustainable practices mean that controlling results also lead to sustainable practices?

So, without any doubt, investments must be made in the recovery of the existing architectural heritage, in particular of that heritage which is characterized by being a symbol of local housing culture often associated with shared forms of living. These projects of Shared Living Heritage (SLH) continue to be an element of valorization of local communities and an actor promoting the sustainable development of territories.

To some extent, it is clear that normative and superordinate design actions need to be adopted for the sustainable development of territories without compromising the freedom of creativity and the use of natural resources and participation of local communities (Figure 10). 


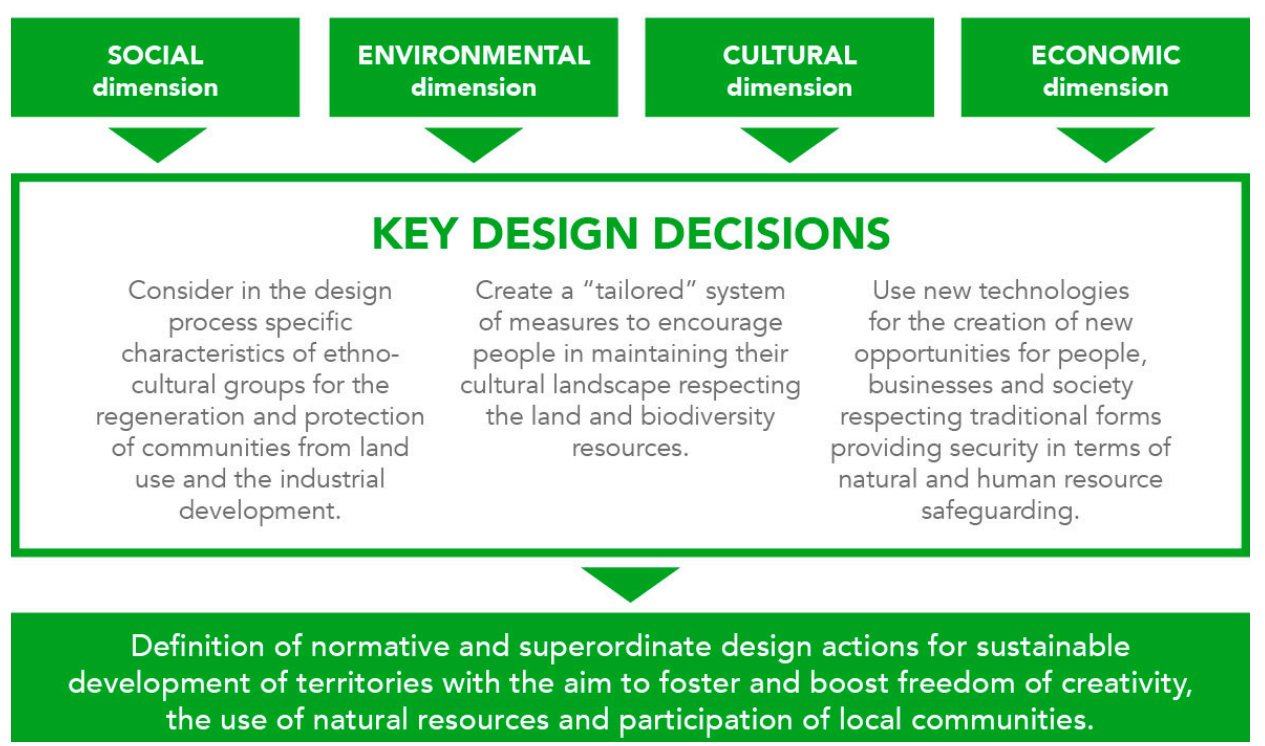

Figure 10. Key design decisions for the regeneration of shared-living heritage.

With this study, we also tried to demonstrate an approach to democratize the heritage regeneration process design approach and to preserve the identities of communities by, for example, looking at city development, real estate market, and sometimes the unavoidable slowness of local governments to cope with necessary changes. Thus, it is necessary to enhance the skills and awareness of communities in the field of sustainability, culture, and traditions in order to take into account during the design process the specific characteristics of ethnocultural groups for the regeneration and protection of communities from land use and the industrial development.

In the area of shared-living heritage, it is necessary to develop a series of measures so that the communities could foster and thrive their culture and products. By creating sustainable business opportunities through regeneration and being self-sustained, this will help to build a balance between governments top-down approaches and citizen bottom-up engagement. Alongside this, policymakers along with designers, citizens' representatives, and stakeholders need to create a "tailored" system of measures to encourage people to maintain and steward their cultural landscape respecting the land and biodiversity resources. Moreover, it is still necessary to provide sustainable perspectives in terms of living conditions, work opportunities, housing, services to the locals, engaging in innovative models of growth within traditional economic, and working activities. In this regard, new technologies, such as the internet of things, $5 \mathrm{G}$ telecommunication, new mobility models, new transportation services by drones and other devices, etc., are creating new opportunities for people, businesses, and society in remote places respecting traditional forms providing security in terms of natural and human resource safeguarding. In other words, it is necessary to cooperate to create resilient, sustainable, and prosperous communities.

Once these issues have been outlined by this work, the following steps for the research can be directed toward a better understanding of the reasons why some typologies have better and more uniform behavior in terms of territorial sustainability. A deeper analysis, able to support the definition of guidelines for governments, associations, entrepreneurs, and citizens can be relevant to understand how to realize (with public policies or design strategies) regenerative interventions, so as to improve and maximize the benefits in terms of sustainable impacts on territories.

Author Contributions: Conceptualization, T.C. and E.G.; methodology, T.C.; validation, T.C., E.G., M.F. and V.B.; formal analysis, T.C. and E.G.; investigation, T.C., E.G., M.F., and V.B.; resources, T.C., E.G., M.F. and V.B.; data curation, E.G., V.B.; writing-original draft preparation, T.C., E.G., M.F., and V.B.; writing-review and editing, T.C., E.G., M.F. and V.B.; visualization, E.G.; supervision, T.C.; project administration, E.G., M.F. and V.B.; funding acquisition, T.C. All authors have read and agreed to the published version of the manuscript.

Funding: This research was funded by "Shanghai 1000 Talent Plan" award number SX06077. 
Acknowledgments: The research project was performed within a long-term international collaboration between the Environmental Futures Lab. at the College of Design and Innovation, Tongii University in Shanghai (China), the School of Architecture, Art and Design of Tecnologico de Monterrey (Mexico), and the China Lab. for Architecture and Urban Studies of the University of Pavia (Italy), under the supervision of Tiziano Cattaneo and Emanuele Giorgi. Data and documents only available in the Chinese language have been translated by Minqing Ni. The authors would like to thank all the Experts, who dedicated their time and actively participated in several meetings and discussions. We also thank the three anonymous reviewers for their valuable and helpful comments and the editors for their constant support. And especially we would like to express our deep gratitude to Professor R. Brooks Jeffrey (Associate Vice President for Research at the University of Arizona's Office of Research, Innovation \& Impact) for dedicating his time and knowledge to support this project, and also for proofreading our manuscript.

Conflicts of Interest: The authors declare no conflict of interest.

\section{Appendix A}

The narrative descriptions of the projects.

\section{Appendix.A.1. Cascina}

Cascina Cuccagna (2011); Milan, Italy; Associazione Consorzio Cantiere Cuccagna (ACCC): Changing its role from agriculture to a place of culture and meeting, and after years of neglect, this project becomes an oasis to socialize within the urban grid of Milan that seeks to improve the lives of its residents. Exhibitions, culture, culinary activities are activities that are sought to be developed in this Cascina that refuses to disappear, generating a new identity more in keeping with its current reality.

Co-Housing Chiaravalle (2016); Milan, Italy; Cohousing.it: Creating community is the objective of this recovery project for a Cascina from the 8th century. Surrounded by large garden areas and spaces to promote common activities among residents, this project is friendly to the environment using renewable energy. Between history and a modern lifestyle, this set of 50 houses offers the possibility of generating a change in the lives of their owners.

Cascina Roccafranca (2007); Turin, Italy; Turin's University, ANCI, and Foundation Cascina: This project is based on regulations that promote collaboration between citizens and government institutions and seeks to regenerate numerous abandoned industrial buildings. Located in a city with experience in regeneration and redevelopment such as Turin, it seeks through this intervention to use buildings and vacant lots to fight against the social exclusion of the residents of these neighborhoods, generating social enterprises and centers for community participation, in order to reduce poverty, unemployment and create a space for coexistence. Thanks to various financing programs, to which the city has been credited, it is that projects like this can be carried out.

\section{Appendix.A.2. Hacienda}

Hacienda Niop (2014), Campeche, Mexico; R79 + AS ARQUITECTURA: The balance between the history of a hacienda and a new use that offers a resting space for its visitors results in this Boutique Hotel project in an old abandoned hacienda in southern Mexico. The need for new uses to their spaces, in accordance with a new identity and respect for the essence of the original buildings and exterior spaces, guide this project to ensure that they coexist despite their contrasting times and uses.

Hacienda San Pedro Celso Garza Guajardo (1990); Nuevo Leon, Mexico; Autonomous University of Nuevo León: This project recovers a 17th-century hacienda for the creation of a center that exhibits regional history. This center has a library, museum, exhibition rooms that at the same time function as a space for workshops and meetings, as well as an open-air theater. Managed by a public university, this project allows the use of some of its areas for institutional activities, educational or cultural activities for the entire public.

Hacienda San Antonio Chablé (2017); Chocholá, Yucatan, Mexico; Central de Proyectos SCP: Restoring a 19th-century hacienda and turning it into a hotel, the spaces were adapted for their new activities. Some spaces were decided to be intervened, and very interesting spaces were created, mixing the old and the new. The recovery of this space also contemplated the natural landscape, mainly the flows that fed a cenote, which is the heart of the project. In other spaces that had become ruins, they were left intact as a reminder of the relentless passage of time. 
Appendix.A.3. Tulou

Tulou renovation project (2019); Fujian, China; Rural Urban Framework + University of Hong Kong: A collaboration between Rural Urban Framework and University of Hong Kong has given Tulou Zhenchunlou two buildings that provide the community with spaces for coexistence and recreation. Being Zhenchunlou, the first Tolou to appear in the village of Lantian, China, was abandoned for decades until the intervention by Rural Urban Framework. Made of wood, combining ancient and modern techniques, these structures, a tower and a trumpet, which is born in a first-level window and opens until it ends up resting in a patio, forming some bleachers. They have become part of daily life for the inhabitants of the community by developing activities such as study, coexistence, or the presentation of events.

School Bridge (2009); Fujian, China; Li Xiaodong Atelier: More than just satisfying the need to cross a river, this project pushes functionality to the limit by not only giving the community a connection between the two ends of a river, but also a school, a library and a store. It is also an attraction for the elderly and children to spend time on it. Located in the town of Hakka Xiashi, Fujian province in China, this project can become the key to revitalize this town that was facing aging and neglect of its inhabitants. An example of collaboration between designers and users to achieve a multi-functional project in harmony with its surroundings and its history.

Community-led design in China (2018); Fujian, China; AzuKo + Hello Shenzhen: five examples of participatory design projects. Cha'er Hutong Children's Library and Art Center in Beijing, Xihe Village Cooperative in Henan Province, Angdong Health Center in Hunan Province, and the Hada Village Water Community Center and Taoshu Tulou, both in Fujian province. These projects by Azuko (an architectural charity serving disadvantaged communities) show us a design led by the community for a humanitarian impact and the development of these communities. A design methodology, such as the one used, focused less on the economic and more on the human helps to achieve the objective of a local vision and appropriation of the project, taking into account the strengths of the community and disregarding its problems or differences, to achieve a solid project that meets the expectations of all participants and users.

\section{Appendix.A.4. Marae}

Te Noho Kotahitanga Marae (2012); Albert campus, New Zealand; Lyonel Grant: This Marae, located at the New Zealand University of Technology, is a spiritual place built in a sustainable way and combines the tradition with a contemporary environmental sensitivity. Its main function is to gather people for ceremonial services and celebrations, and also it is a repository of regional historical knowledge. This project is complemented by a dining room for 200 people. Since the concept, this project has shown the spirituality necessary for the functions it was designed for.

Tanatana Marae (2019); Waimana, New Zealand; Apa Architects: Project designed for a community with the ceremonial function of living in mourning for a deceased relative. This duel lasts three days and all his relatives accompany the body in this building that is complemented by another nearby construction in which the family's valuable objects are stored. It also has sustainable elements for water reuse, light sensors, thermal materials, and self-sufficient waste disposal. It has all the necessary services to become a space to remember the family member who has left, rest with him, and being with him in his last moments in this life.

Pehiáweri Marae (1980); Glenbervle, Whangarel, New Zealand; Ongoing regional regeneration project: This research project seeks to address the problem of homelessness for Maori people through the collaborative design together with the community, so they are involved in the entire design process. The project contemplates groups of houses of different characteristics with the necessary flexibility to allow community life and, at the same time, maintain the privacy of each family. 


\section{Appendix B}

Experts' names and a short description of their background:

Expert \#01-Roberto Cárdenas Martinez-Professor at the Universidad Tecnológica de México S.C. Expert in the conservation of the architectural heritage. Professor Cárdenas has also experience in the Italian context having spent a period of research and teaching at the Università degli Studi di Napoli Federico II

Expert \#02-Enrico Valentino Hernández-Lecturer at the Tecnologico de Monterrey, College of Architecture, Arts and Design. Chair of the 3ME Arquitectura in Guanajuato Mexico. Their expertise comes from the development of projects around traditional 18th-century buildings of Central Mexico. Rehabilitation of historic places and the preservation of cultural landscapes is their main focus.

Expert \#03-Gregorio de la Rosa-Lecturer at Tecnologico de Monterrey, College of Architecture, Arts and Design. He is an expert in the historic preservation of 16th-century architecture, particularly religious and recreational buildings. He has over 30 years of experience in preservation projects in Central and Southern Mexico. He is a consultant at Instituto Nacional de Antropología e Historia at the regional and national levels.

Expert \#04-Sara Broglio-PhD, Senior Structural Engineer, and leading specialist in resilient structural systems at Aurecon, Canterbury, New Zealand. Dr. Sara Broglio has experience in both Italy and New Zealand involved in a series of academic activities including research, laboratory classes on structural regeneration of historical buildings. In particular, being a young professional she is active in community engagement and social projects in West Coast, New Zealand.

Expert \#05-Angelo Bugatti-Advisory professor at Tongji University, Shanghai, China, and former professor in architecture and urban design in Italy. Professor Angelo Bugatti has over 30 years of experience in research, teaching, and design in Italy, China, and Central America including Mexico. Director of the 15 editions of the International Design Seminar "Urban Culture and Landscape Renewal", he was the coordinator for Scientific Agreements between the University of Pavia, the Universidad Federal da Bahia, and the Universidad Central Santiago del Chile and the Tongji University of Shanghai.

Expert \#06-Aldo Castellano-Professor of history of architecture at the Politecnico di Milano, Italy. He has 40 years of academic activities. He was also: founder and vice president of the Italian Society for Industrial Archeology, (1975-1980); deputy editor of L'Arca magazine, (1986-1991); director of the Architecture section of the Bompiani Dictionary (1987); founder and vice president of RURAL_IA Onlus (1998-2000); member of the Commission for the landscape of the Municipality of Milan (2009-2012). He has carried out, and continues to carry out, studies and research with publications on the problems of conservation and reuse of cultural heritage.

Expert \#07-Eugenio Mangi-PhD, Assistant professor at the Department of Architecture and Built Environment, The University of Nottingham, Ningbo China. Dr. Mangi has over 10 years of experience in China, both in academia and in practice, being a researcher and co-founder of the firm Draftarch realizing several projects in China. The participation in the design process of the local communities is the core of his activities for the regeneration and conservation of architecture and heritage buildings.

Expert \#08-Minqing $\mathrm{Ni}-\mathrm{PhD}$, Lecturer in environmental design at College of Design and Innovation, Tongji University, Shanghai, China. Executive Director/Coordinator of the Tongji DESIS $\mathrm{Lab}$ (Design for Social Innovation and Sustainability). She is an active designer and researcher. Her activities focus on the topic "Design intervention based social innovation" exploring possible actions linking the sustainable and ecological lifestyle of communities and understanding of the relationship between the social and the public space.

Expert \#09-Dan Zhu—Architect, Executive manager of the @Design Square of Tongji University. Graduated in Architecture in USA at the University of Cincinnati College of Design, Architecture, Art, and Planning. In Shanghai, she is well recognized by the civic society as a leading specialist in sustainable design and organizer of scientific meetings and public meetings for the study and dissemination of sustainable culture in China and America. 
Expert \#10-Elisabetta Venco-PhD, Researcher/Assistant professor in urban planning and sustainability, Department of Civil Engineering and Architecture, University of Pavia, Italy. Dr. Venco is a young researcher with significant researches carried on methodological approaches to improve the development of the Rural-urban context focusing on urban approaches to analyze and enhance cultural heritages' contexts.

Expert \#11—Caterina Pietra-PhD, Candidate in design, modeling, and simulation in engineering at the Department of Civil Engineering and Architecture, University of Pavia, Italy. Thanks to her study experience between China and Italy, in 2018 she got a Double Master Degree in Building Engineering and Architecture from Pavia University and Tongji University in Shanghai on the topic of "Heritage Conservation and Urban Regeneration in China". In 2019 she was a visiting researcher at the College of Design and Innovation of Tongii University. In Italy, she is involved in several citizens' groups' activities in rural areas of Lombardy.

\section{Appendix C}

The following table represents the values from the Expert Review.

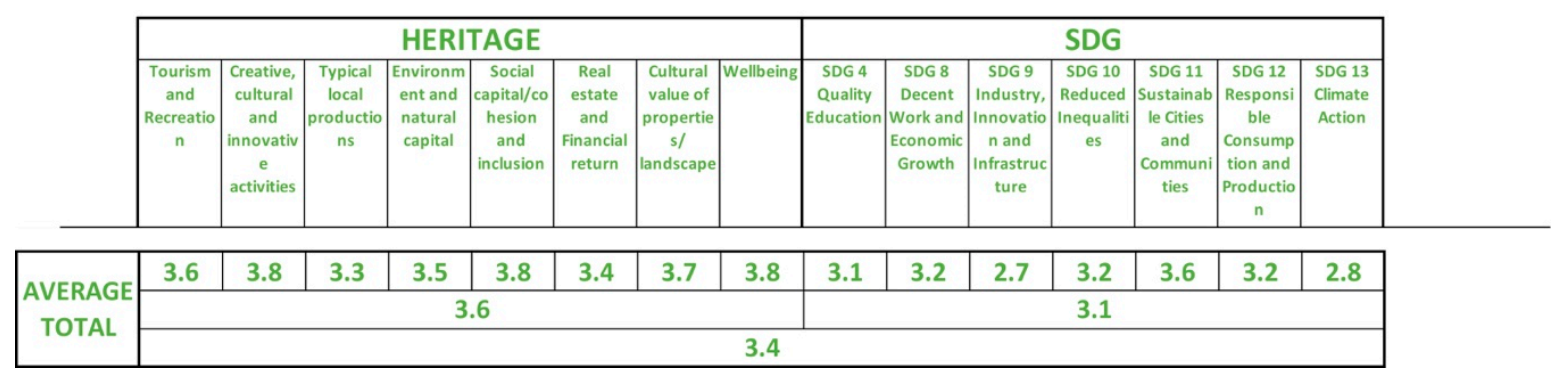

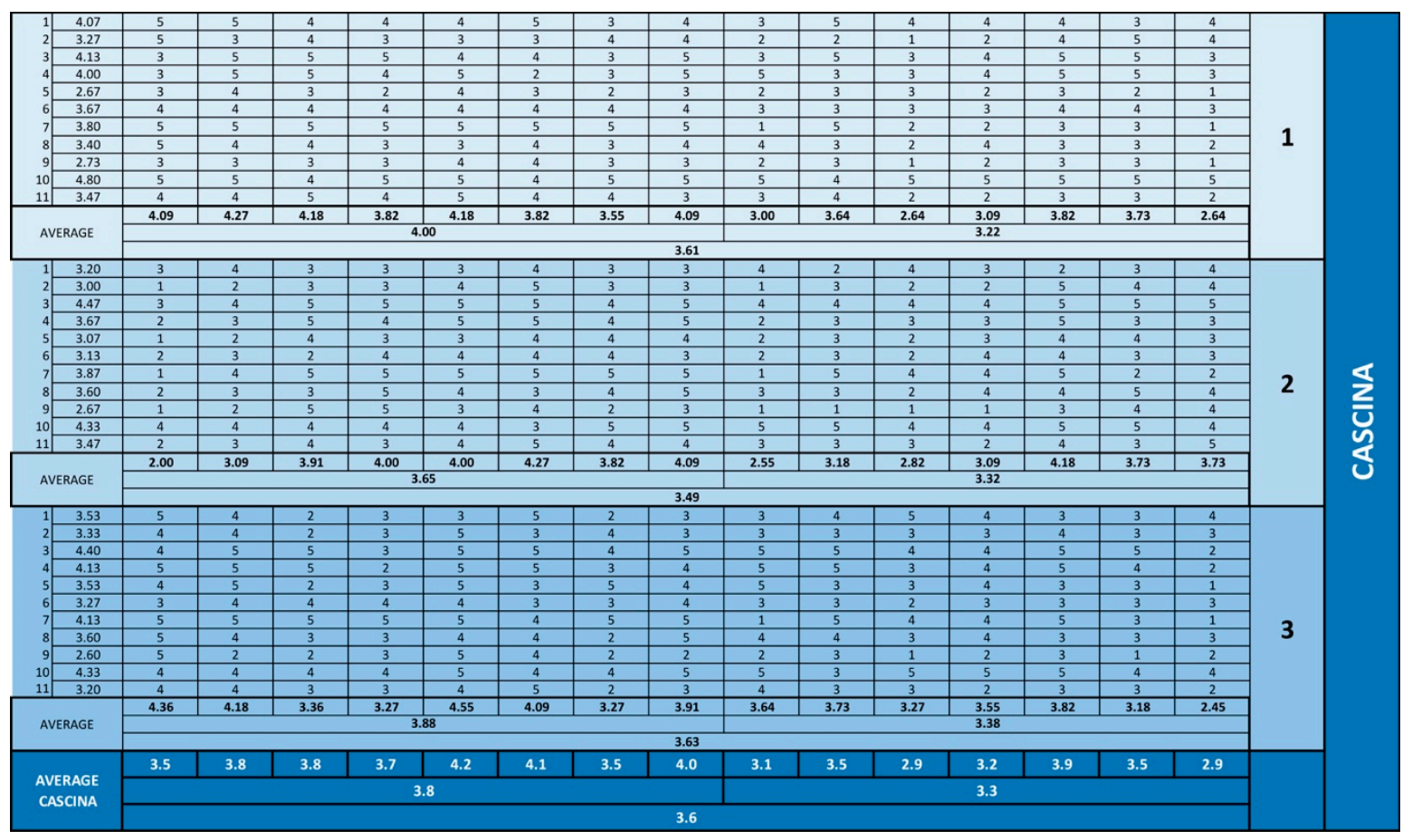



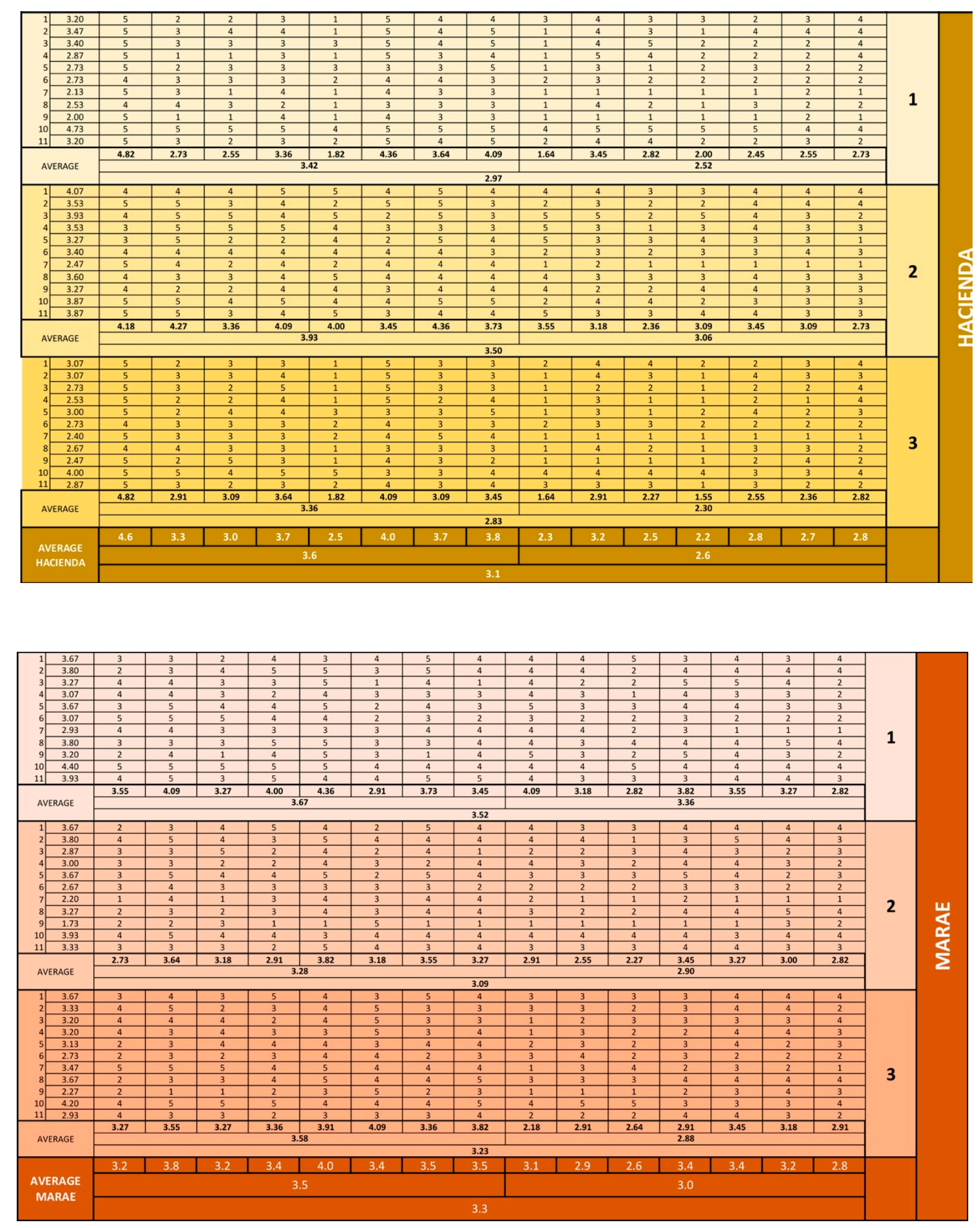


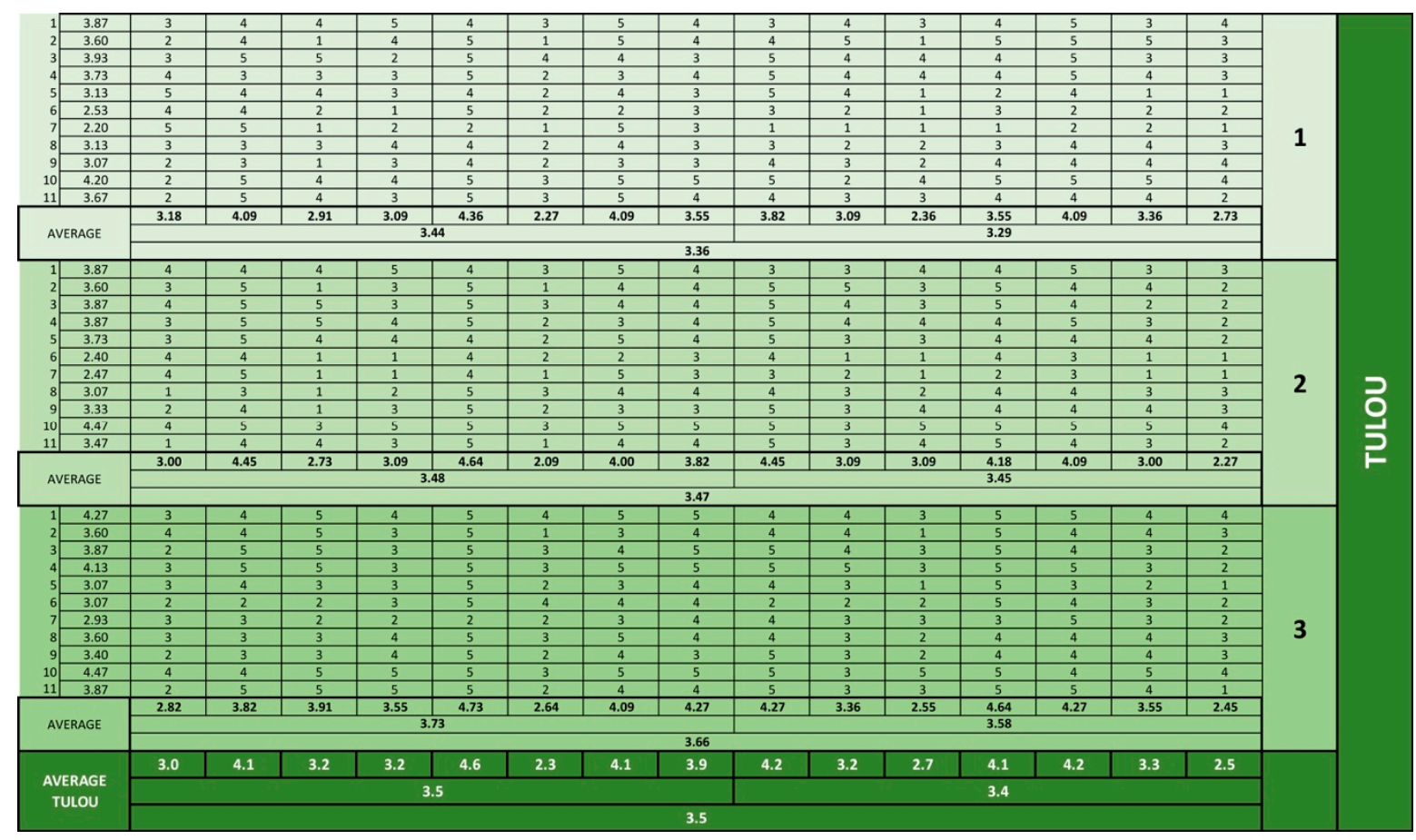

\section{References}

1. Brebbia, C.A.; Galiano-Garrigos, A. Urban Regeneration E Sustainability; WIT Press: Southampton, UK, 2017.

2. Girardet, H. Sustainability is unhelpful: We need to think about regeneration. Available online: https: //www.theguardian.com/sustainable-business/blog/sustainability-unhelpful-think-regeneration (accessed on 2 June 2020).

3. Kamrowska-Załuska, D.; Obracht-Prondzyńska, H. Urban regeneration in urban functional areas in Poland as an instrument of implementation of the EU Cohesion Policy. Growth Chang. 2020, 51, 278-301. [CrossRef]

4. Li, X.; Zhang, F.; Chi, E.; Wei Lan, H. Collaborative workshop and community participation: A new approach to urban regeneration in China. Cities 2020, 102, 102743. [CrossRef]

5. Grijalba, O.; Urrutia, N.; Eizaguirre-Iribar, A.; Irulegi, O.; Hernández, R. Impact of the Public Management Model on the Implementation of Urban Regeneration Policies: Evidence of the Case of the Basque Country, Spain. Plan. Pract. Res. 2020, 35, 302-319. [CrossRef]

6. Azadeh, L.; Mahdi, G.; Timothy, J. Urban regeneration through heritage tourism: Cultural policies and strategic management. J. Tour. Cult. Chang. 2019, 1-18. [CrossRef]

7. Wang, Y.; Bramwell, B. Heritage protection and tourism development priorities in Hangzhou, China: A political economy and governance perspective. Tour. Manag. 2012, 33, 988-998. [CrossRef]

8. Güzey, O. The last round in restructuring the city: Urban regeneration becomes a state policy of disaster prevention in Turkey. Cities 2016, 50, 40-53. [CrossRef]

9. Ghada, K.; Tarek, I. Urban Regeneration Challenges of Heritage Cities Using GIS (Luxor City Case Study). In Proceedings of the 1st International Conference on Towards a Better Quality of Life, El-Gouna, Egypt, 24 November 2017; pp. 1-12.

10. Serrano-Jiménez, A.; Lima, M.L.; Molina-Huelva, M.; Barrios-Padura, A. Promoting urban regeneration and aging in place: APRAM-An interdisciplinary method to support decision-making in building renovation. Sustain. Cities Soc. 2019, 47, 101505. [CrossRef]

11. Della Spina, L.; Lorè, I.; Scrivo, R.; Viglianisi, A. An Integrated Assessment Approach as a Decision Support System for Urban Planning and Urban Regeneration Policies. Buildings 2017, 7, 85. [CrossRef]

12. Giorgi, E. Sharing as Cultural Preexistence. In The Co-Housing Phenomenon. Environmental Alliance in Time of Changes; Giorgi, E., Ed.; Springer Nature: Cham, Switzerland, 2020; pp. 59-91. 
13. Cattaneo, T.; Giorgi, E.; Ni, M. Landscape, Architecture and Environmental Regeneration: A Research by Design Approach for Inclusive Tourism in a Rural Village in China. Sustainability 2019, 11, 128. [CrossRef]

14. Bastian, O.; Grunewald, K.; Syrbe, R.U.; Walz, U.; Wende, W. Landscape services: The concept and its practical relevance. Landsc. Educ. 2014, 29, 1463-1479. [CrossRef]

15. Walz, U. Landscape structure, landscape metrics and biodiversity. Living Rev. Landsc. Res. 2011, 5, 35. [CrossRef]

16. Bastian, O.; Walz, U.; Decker, A. Historical landscape elements: Part of our cultural heritage-A methodological study from Saxony. In The Carpathians: Integrating Nature and Society towards Sustainability; Kozak, J., Ostapowicz, K., Bytnerowicz, A., Wyzga, B., Eds.; Springer: Berlin/Heidelberg, Germany, 2013; pp. 441-460.

17. Termorshuizen, J.W.; Opdam, P. Landscape services as a bridge between landscape ecology and sustainable development. Landsc. Ecuc. 2009, 24, 1037-1052. [CrossRef]

18. Cattaneo, T.; De Lotto, R. Rural-Urbanism Architecture. Design Strategies for Small Towns' Development; Alinea Editore: Firenze, Italy, 2015.

19. Cattaneo, T.; Sha, Y.; Ji, Y. Architectural design strategies for the rural development in Europe. In Urban Architecture (UA); Heilongjiang Science and Technology Press: Harbin, China, 2015; pp. 109-111.

20. Cloke, P. Counterurbanisation: A Rural Perspective. Geography 1985, 70, 13-23.

21. Phillips, M. Counterurbanization and Rural Gentrification: An Exploration of the Terms. Popul. Space Place 2010, 16, 539-558.

22. Karsten, L. Counterurbanisation: Why settled families move out of the city. J. Hous. Built Environ. 2020, 35, 429-442. [CrossRef]

23. Brown, J.; Hay-Edie, T. Engaging Local Communities in Stewardship of World Heritage: A Methodology Based on the COMPACT Experience; UNESCO World Heritage Centre: Paris, France, 2014.

24. Paganoni, M. Reclaming heritage for UNESCO: Discursive Practices and Community Building in Northern Italy. In Making Publics, Making Places; Griffiths, M., Ed.; The University of Adelaide Press: Adelaide, Australia, 2016; pp. 75-94.

25. Maeer, G. The Values and Benefits of Heritage: Do economists think more than money? APT Bull. J. Preserv. Tecnol. 2014, 45, 57-63.

26. Jarvis, H.; Bonnett, A. Progressive Nostalgia in novel living arrangements: A counterpoint to neotraditional new urbanism? Urban Stud. 2013, 50, 2349-2370. [CrossRef]

27. Zukin, S. Naked City: The Death and Life of Authentic Urban Places; Oxford University Press: Oxford, UK, 2010.

28. Rodwell, D. Managing change in historic urban landscape. Context 2007, 3, 1.

29. United Nations Educational, Scientific and Cultural Organisation. The UNESCO Recommendation on the Historic Urban Landscape; UNESCO World Heritage Centre: Paris, France, 2019.

30. Araoz, G. World-Heritage Historic Urban Landscapes: Defining and protecting authenticity. J. Preserv. Technol. 2008, 39, 33-37.

31. Elefante, C. The Greenest Building Is One That Is Already Built. Forum J. 2007, 21, 26-38.

32. Fromm, D. Seeding Community: Collaborative Housing as a Strategy for Social and Neighborhood repair. Built Environ. 2012, 38, 364-394. [CrossRef]

33. Milliken, W. The Yanomami Are Great Observers of Nature. Survival International. Available online: https:/www.survivalinternational.org/articles/3162-yanomami-botanicalknowledge (accessed on 15 May 2020).

34. Hill, J.; Woodland, W. Subterranean settlements in Southern Tunisia: Environmental and cultural controls on morphology, community dynamics and sustainability. Geography 2003, 88, 23-39.

35. Umali, S. Repackaging "traditional" architecture of the African Village in Zimbabwe. Urban and architectural heritage conservation within sustainability. In Urban and Architectural Heritage Conservation within Sustainability; Hmood, K., Ed.; Intechopen: London, UK, 2018.

36. Groat, L.N.; Wang, D. Architectural Research Methods, 2nd ed.; Wiley: Hoboken, NJ, USA, 2013.

37. Meuser, M.; Nagel, U. The Expert Interview and Changes in Knowledge Production. In Interviewing Experts. Research Methods Series; Bogner, A., Littig, B., Menz, W., Eds.; Palgrave Macmillan: London, UK, 2009; pp. 17-42.

38. Bogner, A.; Menz, W. The Theory-Generating Expert Interview: Epistemological Interest, Forms of Knowledge, Interaction. In Interviewing Experts. Research Methods Series; Bogner, A., Littig, B., Menz, W., Eds.; Palgrave Macmillan: London, UK, 2009; pp. 43-80.

39. Libakova, N.M.; Sertakova, E.A. The Method of Expert Interview as an Effective Research Procedure of Studying the Indigenous Peoples of the North. J. Sib. Fed. Univ. Humanit. Soc. Sci. 2015, 1, 114-129. [CrossRef] 
40. Giorgi, E. The Co-Housing Phenomenon: Environmental Alliance in Time of Changes; Springer Nature: Cham, Switzerland, 2020.

41. Wang, S.-S.; Li, S.-Y.; Liao, S.-J. The Genes of Tulou: A Study on the Preservation and Sustainable Development of Tulou. Sustainability 2012, 4, 3377-3386. [CrossRef]

42. Crotti, S.; Bertelli, G.; Reggio, M.; Vanetti, D. Abaco Degli Edifici nel Parco del Ticino; Alinea Editrice: Firenze, Italy, 2008; pp. 12-31.

43. Van Zantwijk, R. The Aztec Arrangement. The Social History of Pre-Spanish Mexico; University of Oklahoma Press: Norman, OK, USA, 1985.

44. Tapsell, P. Marae and tribal identity in urban Aotearoa/New Zealand. Pac. Stud. 2002, 25, 141-171.

45. Kawharu, M. Environment as a Marae locale. In Kaitiaki: Maori and the Environment; Selby, R., Moore, P., Mulholland, M., Eds.; Huia: Wellington, New Zealand, 2010; pp. 221-239.

46. Cattaneo, T.; Giorgi, E.; Flores, M.; Barquero, V. Booklet for Expert Interview. Territorial effects of shared-living heritage regeneration. Available online: https://www.dropbox.com/s/tp6tuhetr9u8r8z/Expert\%20Interview booklet.pdf?dl=0] (accessed on 15 September 2020).

47. Nocca, F. The Role of Cultural Heritage in Sustainable Development: Multidimensional Indicators as Decision-Making Tool. Sustainability 2017, 9, 1882. [CrossRef]

48. United Nations. General Assembly UN (2015) Resolution Adopted by the General Assembly on 25 September 2015. Transforming our World: The 2030 Agenda for Sustainable Development. Available online: https://www.un.org/en/development/desa/population/migration/generalassembly/docs/globalcompact/A_ RES_70_1_E.pdf (accessed on 26 June 2018).

49. Giorgi, E.; Cattaneo, T.; Ni, M.; Enríquez Alatriste, R. Sustainability and Effectiveness of Chinese Outline for National Tourism and Leisure. Sustainability 2020, 12, 1161. [CrossRef]

50. Henzler, K.; Maier, S.D.; Jäger, M.; Horn, R. SDG-Based Sustainability Assessment Methodology for Innovations in the Field of Urban Surfaces. Sustainability 2020, 12, 4466. [CrossRef]

51. De Lotto, R.; Cattaneo, T.; Giorgi, E.; Venco, E. Coherences and Differences among EU, US and PRC. Approaches for Rural Urban Development: Interscalar and Interdisciplinary Analysis. Sustainability 2017, 9, 537. [CrossRef]

Publisher's Note: MDPI stays neutral with regard to jurisdictional claims in published maps and institutional affiliations.

(C) 2020 by the authors. Licensee MDPI, Basel, Switzerland. This article is an open access article distributed under the terms and conditions of the Creative Commons Attribution (CC BY) license (http://creativecommons.org/licenses/by/4.0/). 